\title{
Life cycle greenhouse gas emissions for last-mile parcel delivery by automated vehicles and robots
}

\author{
By \\ Luyao Li \\ A thesis submitted in partial \\ fulfillment of the requirements for the \\ degree of Masters of Science \\ (Environment and Sustainability) at \\ the University of Michigan
}

April 2021

Thesis Committee:

Professor Gregory A. Keoleian, Chair

Dr. Hyung Chul Kim, Ford Motor Company, Research Scientist 



\begin{abstract}
Increased E-commerce and demand for contactless delivery during the COVID-19 pandemic have fueled interest in robotic package delivery. We evaluate life cycle greenhouse gas (GHG) emissions for automated ground delivery systems consisting of a vehicle (last-mile) and a robot (final-50-feet) in a suburban setting. Small and large cargo vans (125 and 350 cubic feet; V125 and V350) with internal combustion engine (ICEV) and battery electric (BEV) powertrains were assessed for three delivery scenarios: (i) conventional, human-driven vehicle with human delivery; (ii) partially automated, human-driven vehicle with robot delivery; and (iii) fully automated: connected automated vehicle (CAV) with robot delivery. The robot's contribution to life cycle GHG emissions is small (2-6\%). CAV auxiliary loads offset operational benefits from automated driving. Compared to the conventional scenario, full automation results in $7 \%$ lower GHG emissions for the V350-ICEV but 5\% higher for the V125-BEV. Conventional delivery with a V125-BEV provides the lowest GHG emissions, $160 \mathrm{~g} \mathrm{CO}_{2 \mathrm{e}}$ /package, while partially automated delivery with a V350-ICEV generates the most at $450 \mathrm{~g} \mathrm{CO}_{2 \mathrm{e}}$ /package. Sensitivity analysis shows delivery density and fuel economy are key parameters determining GHG emissions for all scenarios, while CAV power requirements and efficiency benefits have a smaller impact on automated scenario emissions.
\end{abstract}




\section{ACKNOWLEDGEMENTS}

I want to thank Dr. Gregory Keoleian and Dr. Hyung Chul Kim for making this thesis project possible. Their wisdom, experience, and support ensured the technical rigor and accuracy of the analysis. Dr. Keoleian has been a great advisor and mentor that has supported and guided me through this challenging time of virtual semesters. I would also like to thank Dr. Xiaoyi He (postdoctoral researcher at the Center for Sustainable Systems) and the environmental science team members at Ford Motor Company, including Dr. Hyung Chul Kim, Dr. Timothy Walling ton, and Robert De Kleine. Their constant support as well as technical and communication expertise were instrumental to the success of the research. It has been an honor to work with all five of these experts. Additionally, I want to express gratitude to my colleague Nick Kemp for his technical, communication, and moral support; and James Gawron at Ford Motor Company for his helpful input and mentorhsip.

This research was supported by the following grant from Ford Motor Company to the Center for Sustainable Systems (CSS) at the University of Michigan: Ford-University of Michigan Alliance Program (N028450). In addition, I wish to acknowledge the following individuals for their valuable contributions: Grace Hsia, Lanette Fuchs, Sonia Petrucci, and Boris Kort-Packard for their helpful insights in parcel delivery; Dr. Nils Smit-Anseeuw and Dr. Jessy W. Grizzle for their expertise in bipedal robots; Steve DiAntonio at Agility Robotics for providing critical information on robots; Dr. Geoff Lewis and Helaine Hunscher for their support and advice throughout my graduate school experience; and my CSS fellows and friends: Hannah Fetner, Stephen Hilton, Maxwell Woody, Meiye Wang, Mengqing Kan, Yabin Dong, and my parents for their helpful feedback and moral support in the past two years. 
The work presented in this thesis was submitted for publication in the journal Environmental Science \& Technology. The publication decision is still pending at this time. 


\section{TABLE OF CONTENTS}

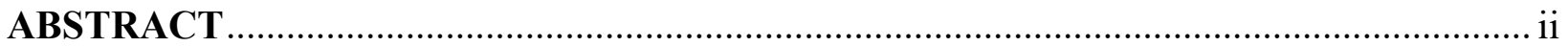

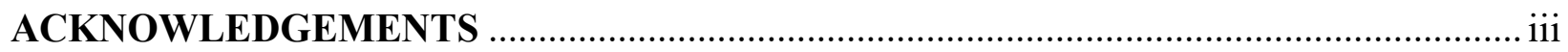

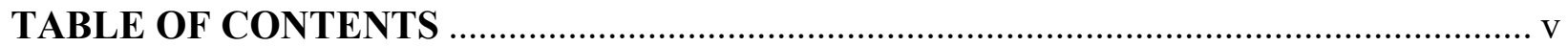

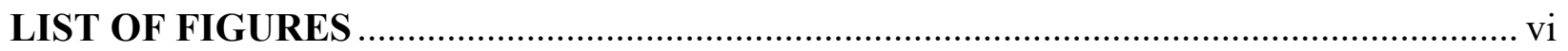

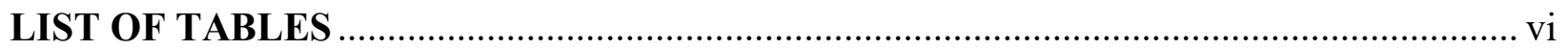

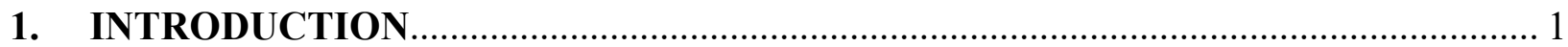

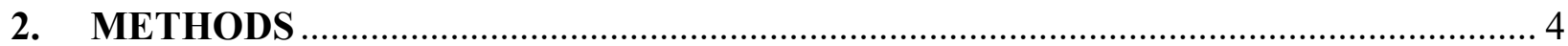

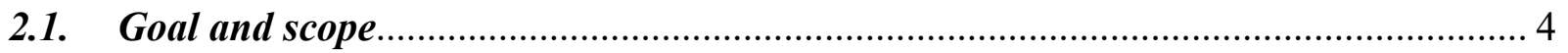

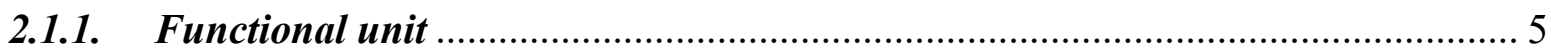

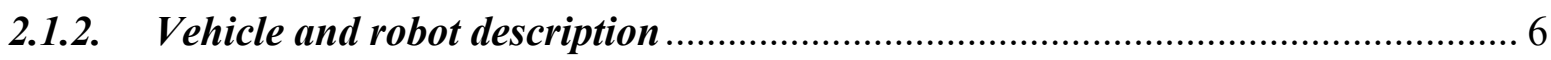

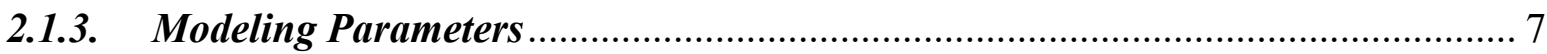

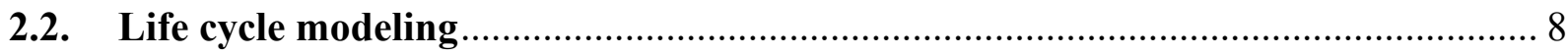

2.2.1. Robot, vehicle, and CAV subsystem usage ...................................................... 9

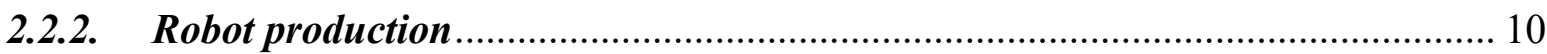

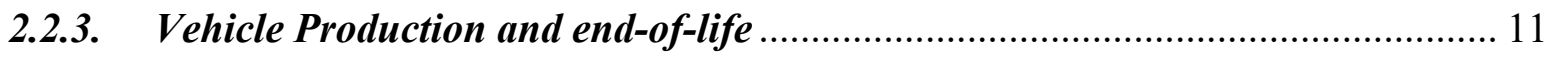

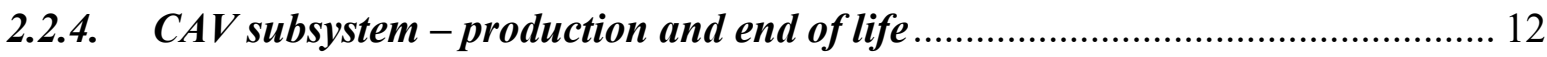

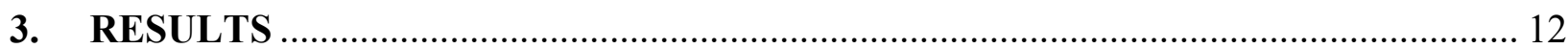

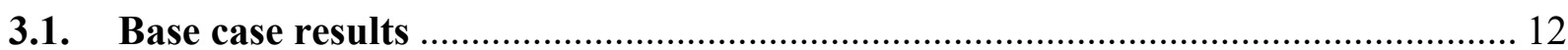

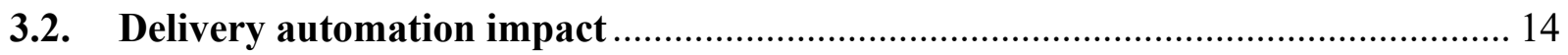

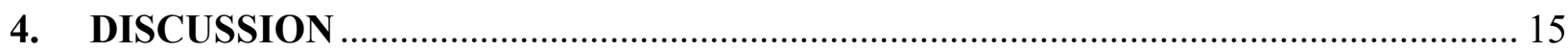

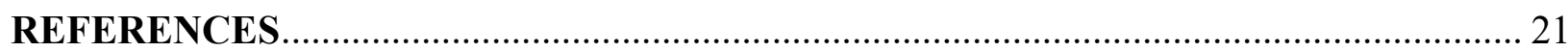

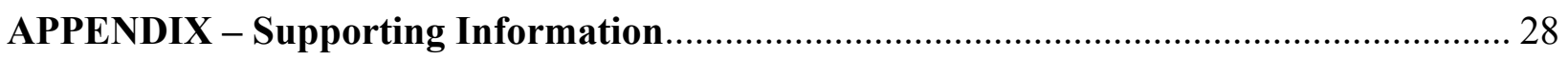




\section{LIST OF FIGURES}

Figure 1. Last-mile delivery LCA system boundary

Figure 2. The last-mile delivery scenarios analyzed in this study considering vehicle class, powertrain type, last-mile delivery vehicle, and final-50-feet delivery method.

Figure 3. Base case life cycle GHG emissions per package for: (i) conventional, (ii) partially automated, and (iii) fully automated delivery scenarios.

Figure 4. Automation impacts on GHG emissions for the V350-ICEV platform, including increased emissions from the robot total (production and use) and CAV subsystem and decreased emissions from eco-driving.

Figure 5. GHG emissions results from our fully automated scenario (curves) for V125 (green) and V350 (orange) with internal combustion engine (solid) or battery electric (dashed) powertrains compared to results from previous studies by Stolaroff et al. (red symbols) and Edwards et al. (blue symbol). Note the results from Stolaroff et al. ${ }^{15}$ and Edwards et al. ${ }^{19}$ are operational only (well-to-wheels or well-to-wings). Our base case results and high delivery density results are indicated on the curves with dots.

\section{LIST OF TABLES}

Table 1. Modeling parameters for base case last-mile delivery model in this study 7

Table 2. Robot material mass breakdown and production burden of primary energy usage and GHG emissions 


\section{INTRODUCTION}

Last-mile delivery, or the last leg of the supply chain moving goods from a local hub (distribution center) to customers, is the most expensive, most carbon intensive, and least energy-efficient supply chain link. ${ }^{1-3}$ Schröderet et al. estimated that fully and partially automated vehicles (including ground vehicles and aerial vehicles like drones) have the potential to reduce delivery costs by $10-40 \%$ in cities, mainly through labor cost savings. ${ }^{4}$ The automated last-mile delivery market has a seven-fold growth potential and expected value of \$11.9 billion by $2030 .^{5}$ Automotive, automation, logistics, and retail companies are investigating how to capitalize on this potential. United Parcel Service (UPS) and Waymo have partnered up for autonomous van delivery testing in Arizona; ${ }^{6}$ Ford is partnering with Agility Robotics to explore package delivery using bipedal robots $;{ }^{7}$ Amazon, Starship, Nuro and FedEx are testing drones and autonomous delivery robots (ADRs). ${ }^{8-12}$ While the use of drones has been the subject of prominent discussions, automated ground delivery using robots offers a wider service area and larger carrying capacity. ${ }^{13-15}$

As automated delivery systems progress, it is important to evaluate their environmental performance and identify applications that lower environmental burdens. These environmental impacts can be quantified using Life Cycle Assessment (LCA) methods which examine all stages of the life cycle of a service, product, or process. Much of the prior research on last-mile delivery evaluated GHG emissions and energy use from an operational perspective but did not examine the production burden and life cycle perspective $\mathrm{e}^{13-16}$.

Production burdens must be considered to gain a comprehensive understanding of the difference between automated versus conventional last-mile delivery. Gawron et al. conducted LCA of a CAV sedan, which included the production burdens of the vehicle as well as the 
sensing and computing subsystem. ${ }^{17}$ They concluded that CAV sedans could reduce energy use and GHG emissions by up to 9\% relative to conventional sedans. Extending Gawron's framework of the CAV subsystem, Kemp et al. conducted an LCA on the deployment of an automated SUV/van as a taxi. ${ }^{18}$ They showed a $1-3 \%$ increase in primary energy use and GHG emissions. However, the life cycle impacts of using a CAV and a robot in last-mile ground delivery have not been analyzed.

Several LCA studies examined last-mile delivery systems and their results are summarized in Table S1. Edwards et al. reported well-to-wheels (WTW) greenhouse gas (GHG) emissions of $181 \mathrm{~g} \mathrm{CO}_{2}$ e per drop for delivery of small, non-food items (like books) by a standard delivery van ( $<3.5 \mathrm{t})$ which has a delivery density of 2.4 packages/mile (120 drops/50 miles). ${ }^{19}$ They concluded that a home delivery operation is likely to generate less $\mathrm{CO}_{2} \mathrm{e}$ than typical customer shopping trips by car or bus. This finding that serving multiple customers (e.g., more than 30) over one route reduces GHG emissions compared to customer pick-up or in-store shopping is supported by other LCA studies. ${ }^{2,20}$ Lee et al. compared class 4-6 vehicles for urban delivery and found that battery electric vehicles (BEVs) have lower life cycle energy use and GHG emissions than their diesel counterparts. ${ }^{21}$ Marmiroli et al. confirmed this finding for lightduty trucks. ${ }^{22}$

Figliozzi investigated the operational GHG emissions of ADRs and demonstrated their potential to reduce GHG emissions in specific delivery scenarios. ${ }^{13}$ Despite the measurable emission benefits of ADRs, they have logistical constraints like limited range, cargo capacity, and the final-50-feet problem. The limited ability of autonomous delivery systems to traverse the distance from curb to door is known as the final-50-feet problem. In conventional delivery systems, the final-50-feet begins when the driver parks the vehicle to perform the out-of-vehicle 
activities and ends when the driver leaves. ${ }^{23,24}$ Combining the connected autonomous vehicle (CAV) for hub-to-home delivery with a robot for the final-50-feet could eliminate the issues with limited range associated with the robot and final-50-feet problem of ADRs. Research on the final-50-feet problem is very limited. An assessment of delivery time but not environmental impacts has been reported for office building delivery in Seattle. ${ }^{25}$ We seek to evaluate environmental impacts of the final-50-feet problem by identifying how using a robot impacts the GHG emissions of last-mile automated delivery systems in a suburban residential setting.

We developed a life cycle model of the delivery vehicle and robot and identified the key parameters influencing their life cycle GHG emissions. The system boundary includes all life cycle stages of the last-mile delivery system: vehicle (for last-mile) and robot (for final-50-feet), as shown in Figure 1. Scenarios were developed to compare impacts for automated vs. conventional (non-automated) delivery. Results are reported on a per-package basis. Sensitivity analyses were conducted to address the uncertainties and variation in robot and CAV operation, delivery scenarios, and electricity carbon intensity. 


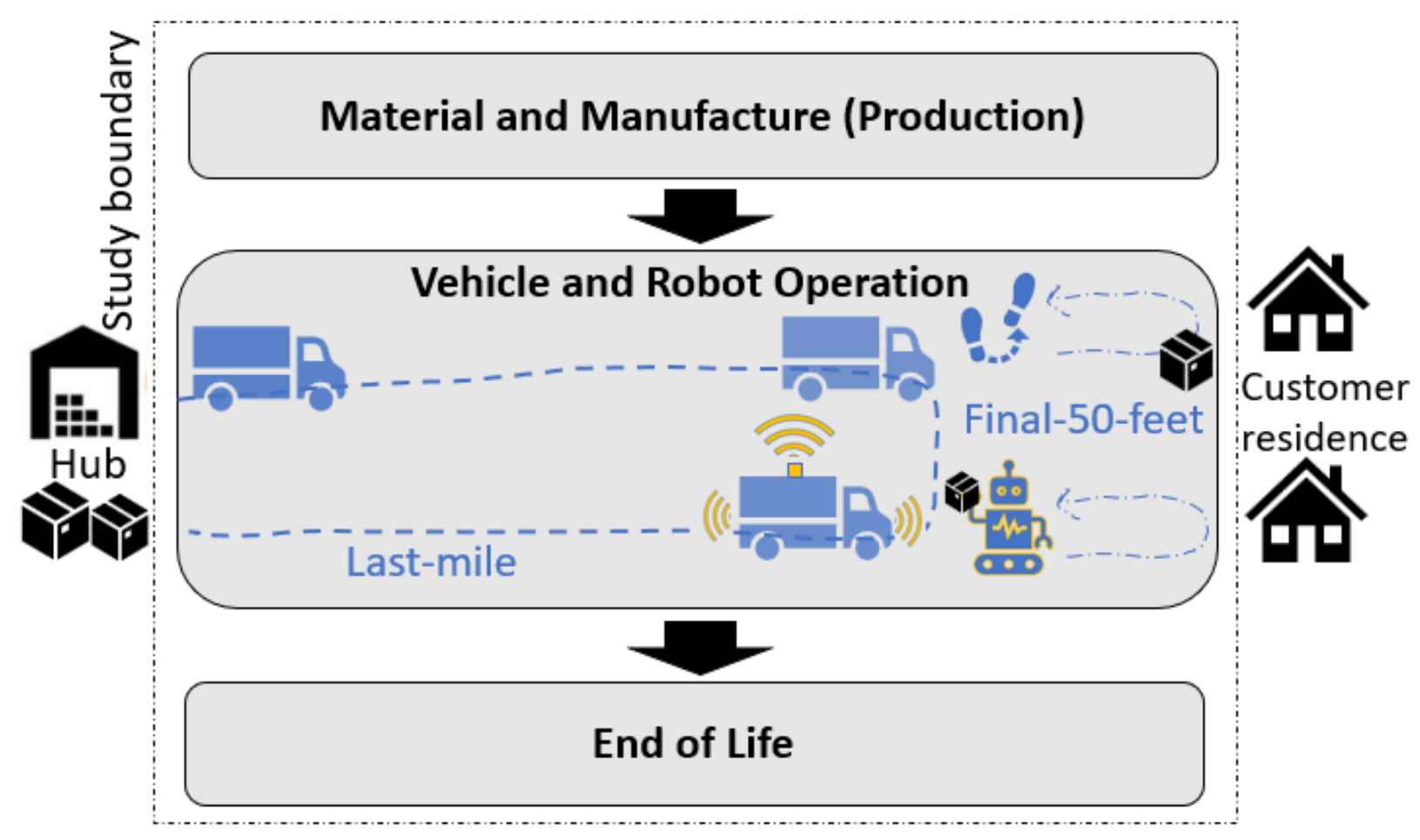

Figure 1. Last-mile delivery LCA system boundary

\section{METHODS}

\subsection{Goal and scope}

Our goal is to understand the GHG emissions from automation of conventional last-mile residential parcel delivery. We use an LCA framework to evaluate the cradle-to-grave GHG emissions for each delivery system, including vehicle and robot production, use, and end-of-life (EOL).

We consider three delivery scenarios and four vehicle platforms, as shown in Figure 2. In the conventional scenario (i), a human drives the vehicle (last-mile) and delivers the package to the doorstep (final-50-feet). In the partially automated scenario (ii), a human drives the vehicle (last-mile) and a robot completes the final-50-feet delivery. The fully automated scenario (iii) 
uses a CAV (last-mile) and a robot (final-50-feet). We note that the partially-automated scenario may not provide cost benefits over the conventional scenario as it adds cost for the robot but still requires a human driver. However, it is included to highlight the robot and the CAV contributions separately. It acts as a proxy of a current demo delivery system that includes a human-driven mothership and sidewalk autonomous delivery robots (SADRs). ${ }^{13}$ A combination of four different vehicle platforms are considered based on two powertrains (internal combustion engine vehicle $[\mathrm{ICEV}]$ and battery electric vehicle $[\mathrm{BEV}]$ and vans with two different cargo volumes (125 cubic feet [V125], and 350 cubic feet [V350]). A comparative analysis of three delivery scenarios is completed for each platform.

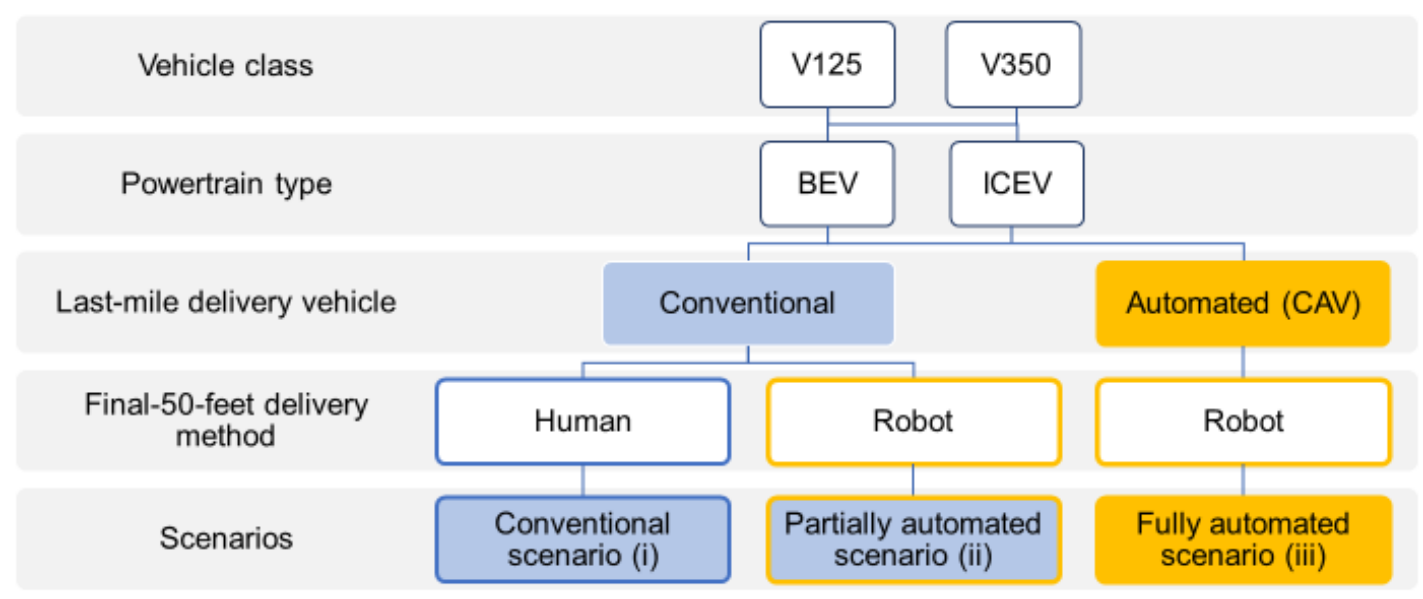

Figure 2. The last-mile delivery scenarios analyzed in this study considering vehicle class, powertrain type, last-mile delivery vehicle, and final-50-feet delivery method.

\subsubsection{Functional unit}

The functional unit is a package delivered to a residential address on a multi-stop route in a suburban area with single family homes (similar to Ann Arbor, MI, U.S.A. population of 
120,000 and area of 28 square-mile ${ }^{26,27}$ ). The packages are assumed to weigh on average $6 \mathrm{~kg}$ using package weight distribution data from the 2012 Commodity Flow Survey (CFS). This is consistent with the maximum cargo weight of the vehicle (703 $\mathrm{kg}$ for V125 and 1,533 $\mathrm{kg}$ for V350) and the carrying capacity of the robot $(30 \mathrm{~kg}){ }^{28-31}$ The package volume is estimated to range from 0.2 to $1.9 \mathrm{ft}^{3}$ as part of our spatial modeling shown in Supporting Information (SI). The number of packages was determined according to spatial modeling of the cargo space (see 2.1.3.) that was informed by personal communications with UPS in Ann Arbor, Michigan, United States. Our base case assumes one package per stop and a distance of 0.5 miles between stops. The sensitivity of route distance and delivery densities are explored. The GHG emissions per package are calculated by dividing the total life cycle impacts of a route by the number of packages delivered. Detailed formulas can be found in the SI.

\subsubsection{Vehicle and robot description}

Two light-duty delivery vehicle classes were considered, the V125 and V350 vans, following the delivery industry standard for cargo volume in $\mathrm{ft}^{3}$. For each vehicle class, an ICEV and BEV were analyzed. The V125-ICEV has a similar cargo volume and maximum payload capacity to the Nissan Cargo Van $\left(122.7 \mathrm{ft}^{3}\right.$ and $\left.676 \mathrm{~kg}\right)$ and the Ford Transit Connect Cargo Van (127.4 $\mathrm{ft}^{3}$ and $703 \mathrm{~kg}$ ). The V350-ICEV was modeled based on the Ford Transit 150 Cargo $\left(357.1 \mathrm{ft}^{3}\right.$ and $\left.1,533 \mathrm{~kg}\right)$.

We used "LDT1" and "LDT2" in Greenhouse gases, Regulated Emissions, and Energy use in Technologies (GREET) to model vehicle production and EOL burdens for the V125 and V350 vans based on similar curb weights. ${ }^{32,33}$ The BEV for both vehicle classes was modeled as the corresponding ICEV plus a battery. We assume that both BEVs have a 200-mile all-electric range (AER) to maintain a reasonable and comparable range performance to the ICEV that can 
serve the delivery area. The CAV subsystem components were taken from the Level 4 CAV subsystem architecture detailed in Kemp et al. as described in section 2.2.4. ${ }^{18}$

A bipedal robot, similar to the Digit model produced by Agility Robotics (Figure $\mathbf{S 2}$ in SI), was modeled for the final-50-feet delivery. ${ }^{34,35}$ Digit is one of the few robots designed to complete the final-50-feet delivery gap. ${ }^{31,36}$

\subsubsection{Modeling Parameters}

Modeling assumptions for the base case are listed in Table 1. Cargo space is the limiting factor for package delivery. ${ }^{22}$ Based on spatial modeling of the cargo space (see SI), we estimate 80 packages for the V125 and 180 packages for the V350 across the three delivery scenarios. Using pre-COVID data from the local delivery industry, we model the delivery route for the V125 and V350 to be 48 and 98 miles (40 and 90 mile routes with an 8-mile round trip from hub to delivery zone) with 80 and 180 packages, respectively, assuming 0.5 miles between stops. This results in a delivery density of 1.67 and 1.84 packages per mile, higher than the 1.51 packages per mile assumed by Stolaroff et al. and lower than the 2.7 packages per mile assumed by Lee et al. ${ }^{15,21}$ In addition, we explored a high delivery density case based on the V350 delivering 180 packages for a route of 48 miles. The sensitivity of the key delivery parameters is also examined. The average vehicle speed between stops for suburban delivery is assumed to be 20 miles/hour. This is comparable to the average speed of 19.6 miles/hour for the Urban Dynamometer Driving Schedule (UDDS). ${ }^{21,37}$

Table 1. Modeling parameters for base case last-mile delivery model in this study 
Packages in cargo (stops per route)

Distance between stops

Distance between hub and delivery

zone

Robot operating power

Robot standby power

Time spent on final-50-ft delivery

Robot lifetime

Vehicle lifetime

Vehicle fuel economy

Average Speed of vehicle

Electricity Grid - carbon intensity

CAV subsystem operating power

CAV subsystem standby power

CAV operational fuel saving ratio
80 for V125 van, 180 for V350 van

0.5 mile

4 miles

$460 \mathrm{~W}^{38}$

$150 \mathrm{~W}^{39}$

$60 \mathrm{~s}$ for human, $100 \mathrm{~s}$ for $\operatorname{robot}^{40}$

$30,000,000$ steps $^{7}$

183,000 miles $^{41}$

24 mpg for V125-ICEV, 14 mpg for V350 ICEV ${ }^{42}$

85 mpgge for $\mathrm{V} 125-\mathrm{BEV}, 47$ mpgge for $\mathrm{V} 350-\mathrm{BEV}^{41,42}$

20 miles/hour ${ }^{21,37}$

U.S. average $-0.43 \mathrm{~kg} \mathrm{CO} 2 \mathrm{e} / \mathrm{kWh}^{41}$

$885 \mathrm{~W}^{18}$

$30 \mathrm{~W}^{18}$

$20 \%(\mathrm{ICEV}), 15 \%(\mathrm{BEV})^{43}$

\subsection{Life cycle modeling}

The life cycle GHG emissions are reported in grams of carbon dioxide equivalent [g $\left.\mathrm{CO}_{2} \mathrm{e}\right]$ on a 100 -year global warming potential $\left(\mathrm{GWP}_{100}\right)$ basis. ${ }^{44}$ The GREET 2020 U.S. average electric grid mix is used (35\% natural gas, $26 \%$ coal, $20 \%$ nuclear, $8 \%$ wind, $7 \%$ hydro, and $4 \%$ other renewables). ${ }^{41}$ The corresponding carbon intensity of the delivered electricity is $0.43 \mathrm{~kg}$ $\mathrm{CO}_{2} \mathrm{e} / \mathrm{kWh}$. 


\subsubsection{Robot, vehicle, and CAV subsystem usage}

The fully automated delivery scenarios are described in the following step sequence (010). Step 0 is defined as the point where the vehicle and robot are stationary at the hub. The vehicle moves from the hub to the delivery zone - step 1 , travels to the delivery locations - step 2 , and returns from delivery zone to the hub after delivering all the packages - step 10 . When the vehicle arrives at the delivery location(s), the robot completes the next series of steps (3-9): 3) unfolding itself, 4) picking up the package from the cargo area, 5) transporting the package, 6) dropping off the package, 7) standing up , 8) returning to the vehicle, and 9) storing itself in the vehicle. ${ }^{40}$ These steps, estimated to be 100 seconds to complete, were characterized by careful analysis of videos published by Agility Robotics (see Table S2). ${ }^{40}$

While the vehicle is traveling the power requirement of the CAV subsystem is estimated to be $885 \mathrm{~W}$ and the robot is considered to be in standby mode $(150 \mathrm{~W}) \cdot{ }^{18,38,39}$ During driving cycles, the CAV realizes eco-driving and intersection connectivity operational efficiency benefits. ${ }^{17,18,43}$ At each delivery stop, the vehicle is shut off in accordance with possible idling restrictions. The CAV subsystem is assumed to be in standby mode during stops and requires 30 $\mathrm{W} .{ }^{18}$ The robot's operational power requirement is $460 \mathrm{~W} .{ }^{38}$ A $90 \%$ battery discharge/charge efficiency is assumed..$^{45}$ This results in $0.012 \mathrm{kWh}$ per package delivery, equivalent to $8 \mathrm{~g} \mathrm{CO}_{2} \mathrm{e} /$ package.

We assume a fuel economy of 24 miles per gallon (mpg) for the V125-ICEV and $14 \mathrm{mpg}$ for the V350-ICEV based on typical city fuel economy for 2020 vans in the United States Environmental Protection Agency (US-EPA) database. ${ }^{42}$ We also assume 85 miles per gallon gasoline equivalent (mpgge) [40 kWh/100 mile] for the V125-BEV based on a 353\% BEV/ICEV fuel economy ratio in GREET, and $47 \mathrm{mpgge}$ [72 $\mathrm{kWh} / 100 \mathrm{mile}]$ for the V350-BEV based on a 
334\% BEV/ICEV fuel economy ratio. ${ }^{41,46}$ This results in WTW GHG emissions of 443, 195, 760, and $354 \mathrm{~g} \mathrm{CO}_{2} \mathrm{e} / \mathrm{mile}$ for V125-ICEV, V125-BEV, V350-ICEV, and V350-BEV, respectively. Delivery densities of $1.67(=80 / 48)$ and $1.84(=180 / 98)$ packages per mile for the V125 and V350, respectively, were used to determine GHG emissions per package.

The CAV subsystem (i.e., computers, sensors, navigation systems, and communication equipment) adds to the vehicle operating load and production burden but provides operational efficiency benefits from eco-driving and intersection connectivity. ${ }^{17,18,47}$ We assume a $20 \%$ reduction in fuel consumption for ICEV and a $15 \%$ reduction for BEV from eco-driving and intersection connectivity. ${ }^{43}$

\subsubsection{Robot production}

The material mass data was provided by Agility Robotics for Digit V3, the latest version of the bipedal robot. ${ }^{38}$ The robot mass is $44.6 \mathrm{~kg}$ and its production energy demand and GHG emissions were estimated based on the material breakdown of components and material production burdens, as shown in Table 2. The material production burdens were derived from GREET $22019 .{ }^{41}$ We modeled "other" material as carbon fiber reinforced composite as it was used in previous versions of Digit. ${ }^{34}$ The EOL and manufacturing data are considered to be negligible.

We assume that the robot lifetime is 30 million steps based on accelerated life testing performed by Agility Robotics. ${ }^{7}$ Using this value we calculated that the robot will deliver 300,000 packages over its lifetime, assuming 100 steps for each package delivery. GHG emissions from robot production are estimated to be $327 \mathrm{~kg} \mathrm{CO}_{2} \mathrm{e}$, of which $43 \%$ are from aluminum production (see Figure S3). Allocating these GHG emissions to the 300,000 delivered packages results in $1.1 \mathrm{~g} \mathrm{CO}_{2} \mathrm{e} /$ package. 
Table 2. Robot material mass breakdown and production burden of primary energy usage and GHG emissions

\begin{tabular}{cccc}
\hline Materials & Mass $\mathbf{( k g})^{38}$ & $\begin{array}{c}\text { Primary Energy } \\
\text { from production } \\
(\mathbf{M J} / \mathbf{k g})^{41}\end{array}$ & $\begin{array}{c}\text { GHG emissions } \\
\text { from production } \\
(\mathbf{k g ~ C O} \mathbf{~} \mathbf{e} / \mathbf{k g})^{41}\end{array}$ \\
\hline Copper & 5.53 & 30.2 & 2.5 \\
Battery & 4.3 & 152 & 9.6 \\
Thermoplastic & 1.45 & 113 & 5.1 \\
Electronics & 1.72 & 374 & 23 \\
Steel & 10.5 & 41.9 & 2.8 \\
Aluminum & 19.66 & 119 & 7.2 \\
Other* & 1.41 & 579 & 38 \\
\hline
\end{tabular}

${ }^{*}$ Carbon fiber composite values are used for other

\subsubsection{Vehicle Production and end-of-life}

Vehicle production GHG emission data were sourced from GREET 2019, as shown in Table S3 ${ }^{41}$ We modeled the V125 vehicle based on the default "LDT1" specifications for both the ICEV and BEV in GREET. The V350-ICEV was modeled based on the default GREET "LDT2" category due to similar curb weights. In addition, the V125 and V350 BEV were modeled from the BEV LDT parameters in GREET. These parameters include battery capacity, fuel economy and AER. Assuming a linear relation between AER and battery size, the battery capacity is estimated to be 89 and $160 \mathrm{kWh}$, respectively, for the V125 and V350 BEV (AER of 
200 miles) ${ }^{41}$ Additional details can be found in the SI. The same method was applied to determine GHG emissions for production and EOL stages of the BEVs. Vehicle weights and production phase primary energy use and GHG emissions are given in Table S3. The vehicle lifetime was assumed to be 183,000 miles for all vehicle platforms to estimate per mile impacts from production and EOL. ${ }^{41}$

\subsubsection{CAV subsystem-production and end of life}

CAV subsystem components were obtained from the Level 4 CAV subsystem architecture detailed in Kemp et al., including eight cameras, five radars, one large light detection and ranging sensor (LiDAR), four small LiDARs, one integrated inertial navigation system (INS), one dedicated short-range communication (DSRC), and four computers. ${ }^{18}$ The CAV subsystem has a total weight of $67.1 \mathrm{~kg}$, total life cycle GHG emissions of $1200 \mathrm{~kg} \mathrm{CO}_{2} \mathrm{e}$ for production and $7 \mathrm{~kg} \mathrm{CO}_{2} \mathrm{e}$ for EOL. ${ }^{18}$

\section{RESULTS}

Results are reported for three autonomous scenarios (conventional, partial, and full) with four vehicles (V125-ICEV, V125-BEV, V350-ICEV, and V350-BEV) for a total of 12 delivery system scenarios.

\subsection{Base case results}

The GHG emissions for the base case are shown in Error! Reference source not found. The primary energy use results have similar trends and are presented in Figure S4 in the SI. For V125, the highest GHG emissions were for the partially automated ICEV scenario (ICEV + robot - $301 \mathrm{~g} \mathrm{CO}_{2} \mathrm{e} /$ package) and the lowest for the conventional BEV scenario (BEV + human - $160 \mathrm{~g} \mathrm{CO}_{2} \mathrm{e}$ / package). V350 scenarios emit 39\% - 56\% more GHG emissions per package 
than the V125 scenarios, despite the slightly higher delivery density (180/98=1.84 vs. $80 / 48=1.67$ packages/mile) than the V125 due to the much lower fuel economy of the V350 than V125, i.e., 14 vs. $24 \mathrm{mpg}(=17$ vs. $10 \mathrm{~L} / 100 \mathrm{~km})$. The number of packages in a truck has a relatively small impact on energy use and GHG emissions per package because the distance between stops is assumed 0.5 miles in the base case. V350 vehicles can deliver more packages than V150 per trip but also cover longer distance, thereby having a similar range of delivery density and miles per package.

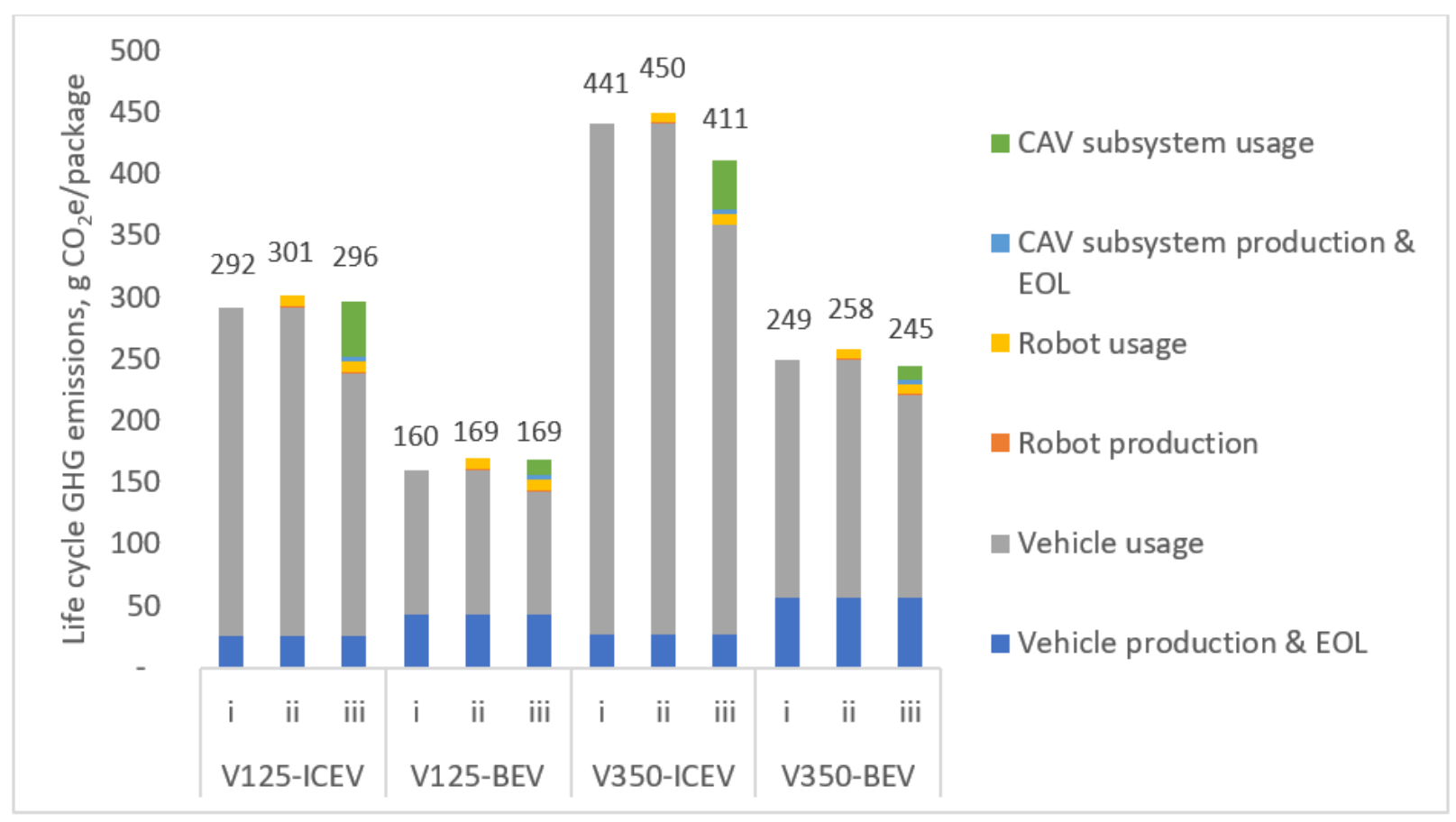

Figure 3. Base case life cycle GHG emissions per package for: (i) conventional, (ii) partially automated, and (iii) fully automated delivery scenarios.

The robot life cycle results in $9 \mathrm{~g} \mathrm{CO}_{2} \mathrm{e} /$ package, and its contribution to overall GHG emissions from the delivery system is relatively small (2-3\% with ICEV, $3-6 \%$ with BEV), as shown in Error! Reference source not found. The vehicle use-phase makes the most 
significant contribution (59-94\%) to total GHG emissions from the delivery system, followed by vehicle production \& EOL (6-27\%). The contribution of the CAV subsystem to life cycle GHG emissions is higher for ICEVs than BEVs, e.g., 15\% for V125-ICEV vs. 8\% for V125-BEV, and $10 \%$ for V350-ICEV vs. 5\% for V350-BEV. The main reason is that the internal combustion engine is more carbon-intensive than central powerplants in generating the electricity used by the CAV subsystem. Meanwhile, the CAV subsystem tends to have a smaller contribution to GHG emissions on larger vehicles (V350) than smaller vehicles (V125).

\subsection{Delivery automation impact}

We define the impact of automation as the difference in results between the fully automated scenario (iii) and the conventional scenario (i). Automation results in a $1.5 \%$ and 5.3\% increase in GHG emissions for the V125-ICEV and V125-BEV. However, for the larger V350 van, there is a $6.7 \%$ (ICEV) and $1.8 \%(\mathrm{BEV})$ decrease in GHG emissions from automation (as shown in Error! Reference source not found.). The 6.7\% reduction in GHG emission for the V350-ICEV platform (see Figure 4) includes $+9 \mathrm{~g} \mathrm{CO}_{2} \mathrm{e} /$ package from the robot, $+45 \mathrm{~g}$ $\mathrm{CO}_{2} \mathrm{e} /$ package from CAV subsystem, and -84 $\mathrm{g} \mathrm{CO}_{2} \mathrm{e} /$ package from eco-driving. Results for V125-ICEV, V125-BEV, and V350-BEV are given in the SI (see Figure S5-S7). 


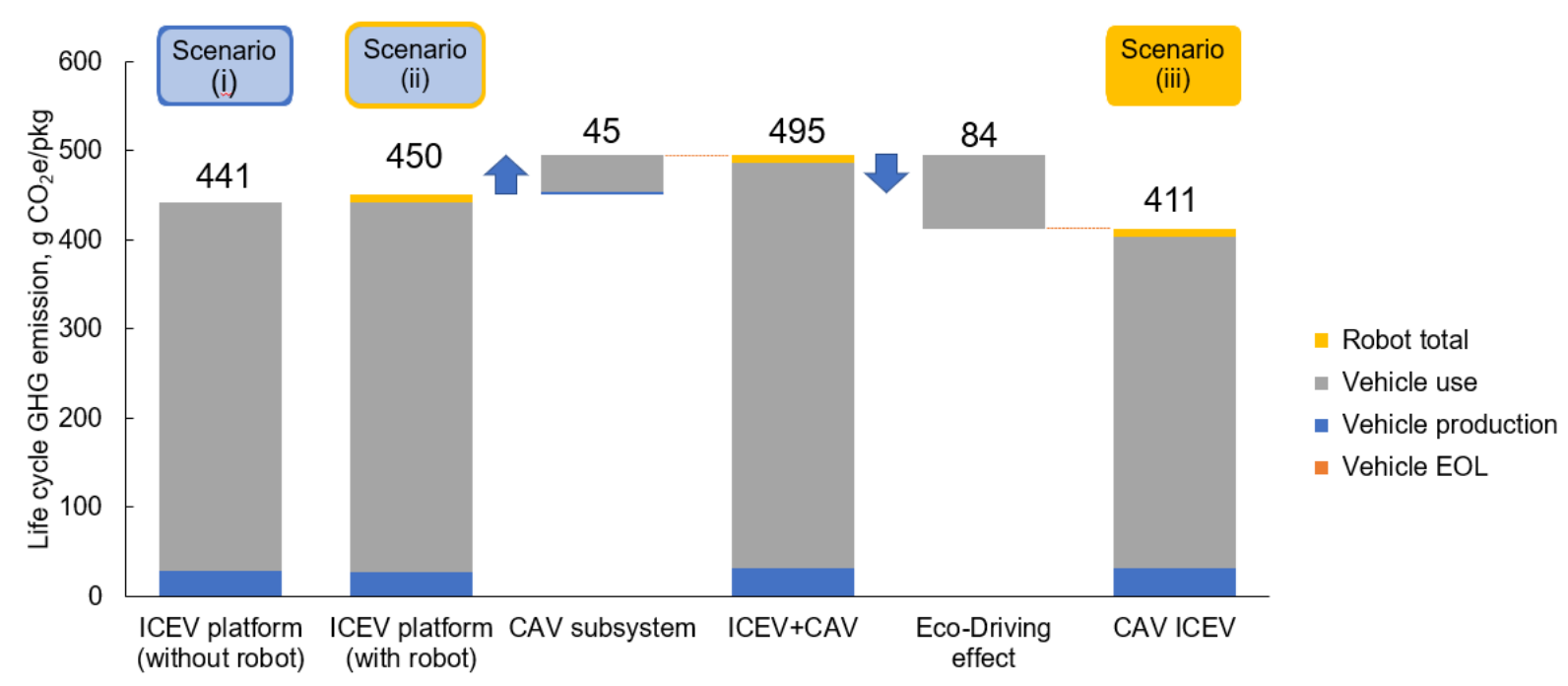

Figure 4. Automation impacts on GHG emissions for the V350-ICEV platform, including increased emissions from the robot total (production and use) and CAV subsystem and decreased emissions from eco-driving.

\section{DISCUSSION}

Further insights regarding potential future development and application of robot automated vehicle delivery systems are discussed below.

The following 10 parameters were varied by $\pm 20 \%$ in the sensitivity analysis: robot operating power, the distance between hub and delivery zone, the number of packages in cargo (stops per route), the distance between stops, robot lifetime, vehicle lifetime, vehicle fuel economy, electricity grid carbon intensity, CAV subsystem operating power, and CAV ecodriving benefits. The results of their impacts on the life cycle GHG emissions per package for the V125 models are presented in the SI. The results for V125-ICEV (see Figure S8) show that the model is most sensitive to the distance between stops $( \pm 16 \%)$, meaning a $20 \%$ increase in the distance between stops, increased life cycle GHG emissions per package by $16 \%$, followed by the vehicle fuel economy $( \pm 14 \%)$, the number of packages in cargo (stops per route) $( \pm 4 \%)$, 
CAV eco-driving benefits ( $\pm 3 \%$ ), and CAV subsystem operating power $( \pm 3 \%)$. The other parameters such as the robot operating power, the robot and vehicle lifetime, the distance between hub and delivery zone, and electricity grid carbon intensity produce minimal impacts $(<1 \%)$ for ICEV. The V125-BEV platform showed a similar trend (see Figure S9).

These findings show that the results are sensitive to the delivery density (i.e., package/total distance), which is related to the distance between stops, the number of packages in cargo (stops per route), the distance between hub and delivery zone, and packages per stop. The GHG emissions per package are lower when the delivery density is higher for both conventional and automated scenarios. In Figure 5, we plotted high delivery density scenario results based on a delivery density of 3.75 packages per mile for V350 covering 48 miles to deliver 180 packages, which clearly shows this trend when compared to the base case results. This implies that the energy and GHG emissions per package will be lower in a dense urban area compared with our base case suburban setting if the other parameters are equal. Figure 5 also shows a comparison of our results with those from two previous studies that reported GHG emissions with delivery density. We note that Stolaroff et al. ${ }^{15}$ and Edwards et al. ${ }^{19}$ data are only for WTW GHG emissions of vehicles and drones. The GHG emissions estimated by Stolaroff et al. ${ }^{15}$ and Edwards et al. ${ }^{19}$ for parcel delivery using vans are generally consistent with our results and lie in the range 200-300 $\mathrm{g} \mathrm{CO}_{2 \mathrm{e}}$ /package. The emissions from delivery using class 4 trucks are much higher than those using vans reflecting the greater fuel consumption of the larger trucks. The drone data indicate that emissions associated with small drones can be much lower, but those from large drones can be much greater than from the V125 and V350 vehicles in our study. 


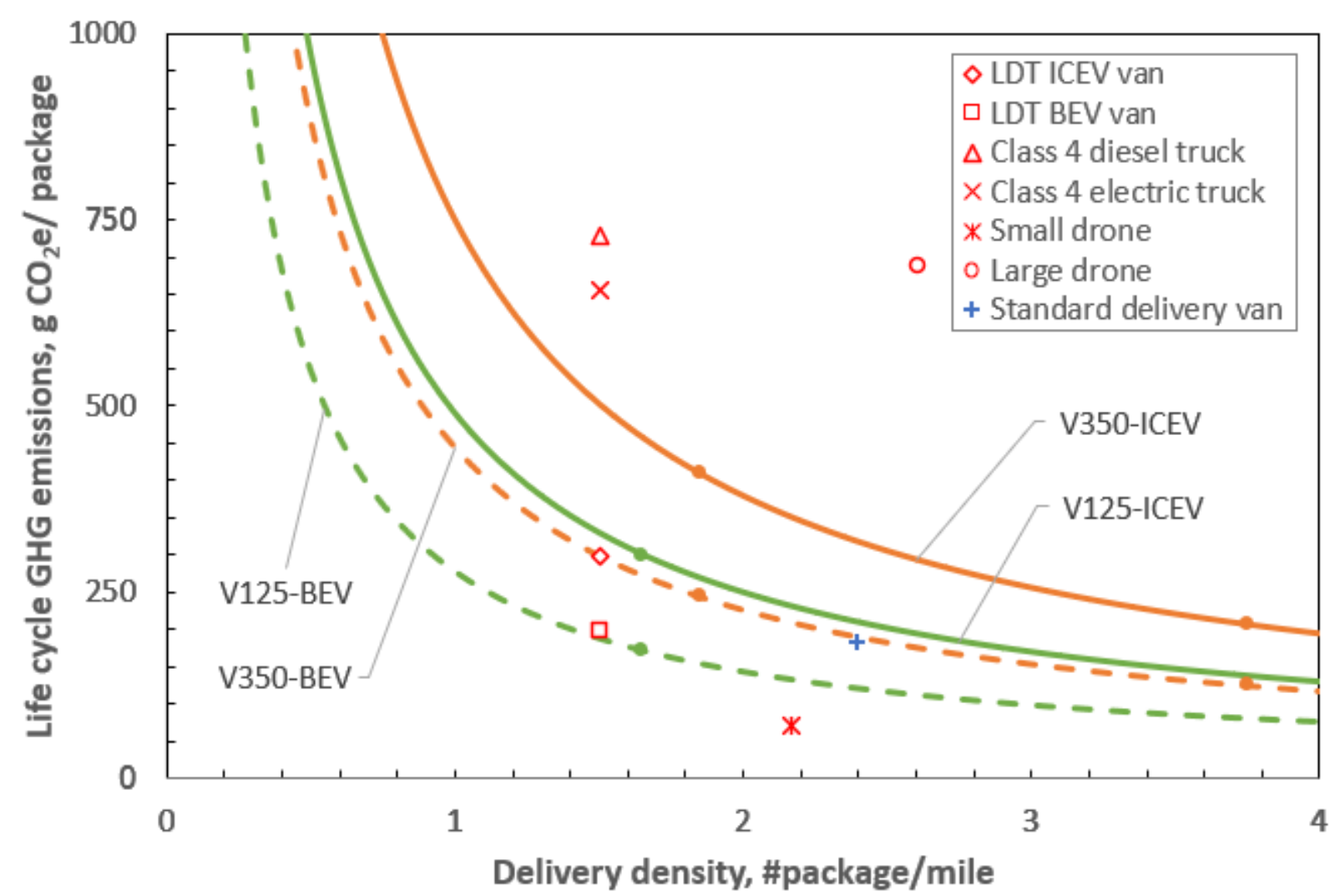

Figure 5. GHG emissions results from our fully automated scenario (curves) for V125 (green) and V350 (orange) with internal combustion engine (solid) or battery electric (dashed) powertrains compared to results from previous studies by Stolaroff et al. (red symbols) and Edwards et al. (blue symbol). Note the results from Stolaroff et al. ${ }^{15}$ and Edwards et al. ${ }^{19}$ are operational only (well-to-wheels or well-to-wings). Our base case results and high delivery density results are indicated on the curves with dots.

Automation results in reduced GHG emissions over the conventional delivery system in cases where the delivery densities are low. This can be explained by the fact that longer distances between stops results in greater eco-driving benefits on a per package basis, which is more likely to outweigh the increased burden from robot delivery at each stop. 
The breakeven delivery densities (see Figure S10) for which automated delivery performs better are $0.05,0.65,1.9$, and 2.5 packages/mile for V125-BEV, V125-ICEV, V350BEV, V350 -ICEV, respectively. However, these results may not apply to rural areas where vehicle fuel economy may increase and the eco-driving savings become smaller.

As the use-phase is the dominant contributor to life cycle GHG emissions, increased fuel economy leads to reduced emissions per package. However, improved fuel economy lowers net automation benefits. For example, increasing the fuel economy of the V350-ICEV by $20 \%$ (from 14 to $16.8 \mathrm{mpg}$ ) decreased the net automation impact on GHG emissions from $-6.7 \%$ to $-3.7 \%$, because the energy savings from CAV eco-driving reduced with the improved fuel economy. Likewise, the automation energy and GHG benefits of more fuel-efficient V125 vehicles are smaller than those of V350 vehicles.

The carbon intensity of electricity generation and the eco-driving benefit are important parameters for the BEV platform. Although our sensitivity analysis calculated the results of changing the grid carbon intensity by $\pm 20 \%$, it is noted that the grid carbon intensity can range from 0.20 (California Mix) to $0.94 \mathrm{~kg} \mathrm{CO} 2 \mathrm{e} / \mathrm{kWh}$ (Hawaii Islands Coordinating Council), resulting in larger variations in GHG emissions per package. ${ }^{41}$ Future grid decarbonization would result in a lower usage contribution (especially for BEV), meaning the potential net automation benefit is likely to decrease. As such, the carbon reductions in the BEV platforms will primarily come from the grid decarbonization in the use phase rather than from the ecodriving benefits.

The operating power of the CAV subsystem is another highly sensitive parameter in the model. We found that if the power consumptions of CAV subsystem can be reduced from $885 \mathrm{~W}$ to $700 \mathrm{~W}$ (see Figure S11), the fully automated scenario for V125-ICEV achieves comparable 
GHG emissions to the conventional scenario. For V125-BEV, the breakeven point is $50 \mathrm{~W}$ for the fully automated scenario to have a GHG emission reduction advantage, which is unlikely.

Although we maintained the same number of packages between conventional and autonomous scenarios, it is reasonable to expect a conventional human delivery system to carry more packages than an automated system. This is because humans can handle a disorganized cargo space, while robots require a well-organized cargo space. However, when there are more packages, the route distance also increases. Thus, the per package impact does not change proportionally. The sensitivity analysis shows that the number of packages handled by a robot or human has a relatively small impact on the result than other parameters. If a human can deliver $20 \%$ more packages per route than a robot ( 216 vs 180 ), the GHG reduction from a fully automated V350-ICEV will be $6.2 \%$ compared with our base case result of $6.7 \%$.

The results suggest that automated delivery systems could have slightly greater life cycle GHG emissions than conventional delivery systems for smaller sized vehicles, but there is more opportunity to reduce emissions for larger sized vehicles. This is because the automation system offers benefits of eco-driving by improving the fuel efficiency in the use-phase; the use-phase has a larger percentage contribution in larger vehicles with lower fuel economy compared to smaller vehicles with higher fuel economy. For all delivery systems, vehicles, and powertrains, the vehicle use-phase is the single largest contributor to GHG emissions, highlighting the need for low-carbon fuels for sustainable parcel delivery. It is also important to pursue low operating power requirements for the CAV subsystem.

We recommend that future research examine optimal delivery performance across the ground and airborne systems based on package size, numbers of deliveries, customer density, vehicle fuel economy, weather restrictions, traffic restrictions, and contactless delivery demand. 
Fully automated delivery with a van and a robot provides similar service to conventional delivery with a van and human delivery in terms of service range and carrying capacity but does not provide significant reductions in GHG emissions.

No single automated delivery system is well suited for all delivery scenarios. Drones and SADRs are limited in delivery range, package size, and carrying capacity, making them suitable for short-distance and small package deliveries. However, as regulations and processes for drone delivery develop, we would expect drones to have shorter delivery times, potentially becoming a preferred method for time-sensitive deliveries especially in a heavy traffic area. SADRs are capable of handling larger packages than drones but their relatively slow speeds $(2 \mathrm{~km} / \mathrm{h})$ may make them less suitable for widespread deployment. ${ }^{13}$ We note that studies of multiple delivery systems need to consider warehouse burden, as many evolving delivery methods, such as drones, require additional infrastructure. ${ }^{15}$ Although there are potential energy savings from using drones compared to conventional delivery, the energy savings are limited relative to the impacts of vehicle fuel economy. ${ }^{29,48}$ Our study focused on delivery scenarios in suburban areas with single family homes that are similar to Ann Arbor, MI. Future research can explore the dense urban delivery scenarios and include robot maintenance and backup systems that may be needed for automated delivery. In addition to environmental performance, life cycle costs and social sustainability factors such as employment impacts are examples of other determinants that can shape the future of automated delivery. 


\section{REFERENCES}

(1) Olsson, J.; Hellström, D.; Pålsson, H. Framework of Last Mile Logistics Research: A Systematic Review of the Literature. Sustain. 2019, 11 (24), 1-25.

https://doi.org/10.3390/su11247131.

(2) Brown, J. R.; Guiffrida, A. L. Carbon Emissions Comparison of Last Mile Delivery versus Customer Pickup. Int. J. Logist. Res. Appl. 2014, 17 (6), 503-521. https://doi.org/10.1080/13675567.2014.907397.

(3) Gevaers, R.; Van De Voorde, E.; Vanelslander, T. Characteristics of Innovations in Last Mile Logistics - Using Best Practices, Case Studies and Making the Link with Green and Sustainable Logistics; 2009.

(4) Schröder, J.; Heid, B.; Neuhaus, F.; Kässer, M.; Klink, C.; Tatomir, S. Fast Forwarding Last-Mile Delivery - Implications for the Ecosystem. McKinsey Co. 2018, No. July, 1-20.

(5) Allied Market Research. Autonomous Last-Mile Delivery Market Size, Trends 2021-2030 https://www.alliedmarketresearch.com/autonomous-last-mile-delivery-market (accessed Oct 4, 2020).

(6) Hirsch, J. UPS and Waymo Start Autonomous Van Delivery Test | Trucks.clom https://www.trucks.com/2020/01/29/ups-waymo-autonomous-van-delivery-test/ (accessed Jun 30, 2020).

(7) Agility Robotics. Agility Robotics on Twitter: "Every journey starts with 30,000,000 steps. https://t.co/6ZK50dhcaM" / Twitter https://twitter.com/agilityrobotics/status/1231012244550537217 (accessed Sep 13, 2020).

(8) Holley, P. Amazon's Autonomous Robots Have Started Delivering Packages in a New Location: Southern California - The Washington Post. The Washington Post. August 12, 
2019.

(9) Starship https://www.starship.xyz/ (accessed Oct 7, 2020).

(10) Baertlein, L. FedEx partners with Walmart, Pizza Hut to test last-mile delivery robot Reuters https://www.reuters.com/article/us-fedex-autonomous/fedex-partners-withwalmart-pizza-hut-to-test-last-mile-delivery-robot-idUSKCN1QG1M7 (accessed Jun 30, 2020).

(11) Amazon.com: Prime Air https://www.amazon.com/Amazon-PrimeAir/b?ie=UTF8\&node=8037720011 (accessed Mar 31, 2021).

(12) Nuro https://nuro.ai/ (accessed Oct 7, 2020).

(13) Figliozzi, M. A. Carbon Emissions Reductions in Last Mile and Grocery Deliveries Utilizing Air and Ground Autonomous Vehicles. Transp. Res. Part D Transp. Environ. 2020, 85. https://doi.org/10.1016/j.trd.2020.102443.

(14) Koiwanit, J. Analysis of Environmental Impacts of Drone Delivery on an Online Shopping System. Adv. Clim. Chang. Res. 2018, 9 (3), 201-207. https://doi.org/10.1016/j.accre.2018.09.001.

(15) Stolaroff, J. K.; Samaras, C.; O’Neill, E. R.; Lubers, A.; Mitchell, A. S.; Ceperley, D. Energy Use and Life Cycle Greenhouse Gas Emissions of Drones for Commercial Package Delivery. Nat. Commun. 2018, 9 (1), 1-13. https://doi.org/10.1038/s41467-017$02411-5$.

(16) Shahmohammadi, S.; Steinmann, Z. J. N.; Tambjerg, L.; Van Loon, P.; King, J. M. H.; Huijbregts, M. A. J. Comparative Greenhouse Gas Footprinting of Online versus Traditional Shopping for Fast-Moving Consumer Goods: A Stochastic Approach. Environ. Sci. Technol. 2020, 54 (6), 3499-3509. https://doi.org/10.1021/acs.est.9b06252. 
(17) Gawron, J. H.; Keoleian, G. A.; De Kleine, R. D.; Wallington, T. J.; Kim, H. C. Life Cycle Assessment of Connected and Automated Vehicles: Sensing and Computing Subsystem and Vehicle Level Effects. Environ. Sci. Technol. 2018, 52 (5), 3249-3256. https://doi.org/10.1021/acs.est.7b04576.

(18) Kemp, N. J.; Keoleian, G. A.; He, X.; Kasliwal, A. Life Cycle Greenhouse Gas Impacts of a Connected and Automated SUV and Van. Transp. Res. Part D Transp. Environ. 2020, 83. https://doi.org/10.1016/j.trd.2020.102375.

(19) Edwards, J. B.; McKinnon, A. C.; Cullinane, S. L. Comparative Analysis of the Carbon Footprints of Conventional and Online Retailing: A "Last Mile" Perspective. Int. J. Phys. Distrib. Logist. Manag. 2010, 40 (1-2), 103-123. https://doi.org/10.1108/09600031011018055.

(20) Van Loon, P.; Deketele, L.; Dewaele, J.; McKinnon, A.; Rutherford, C. A Comparative Analysis of Carbon Emissions from Online Retailing of Fast Moving Consumer Goods. $J$. Clean. Prod. 2015, 106 (2015), 478-486. https://doi.org/10.1016/j.jclepro.2014.06.060.

(21) Lee, D. Y.; Thomas, V. M.; Brown, M. A. Electric Urban Delivery Trucks: Energy Use, Greenhouse Gas Emissions, and Cost-Effectiveness. Environ. Sci. Technol. 2013, 47 (14), 8022-8030. https://doi.org/10.1021/es400179w.

(22) Marmiroli, B.; Venditti, M.; Dotelli, G.; Spessa, E. The Transport of Goods in the Urban Environment: A Comparative Life Cycle Assessment of Electric, Compressed Natural Gas and Diesel Light-Duty Vehicles. Appl. Energy 2020, 260 (November 2019), 114236. https://doi.org/10.1016/j.apenergy.2019.114236.

(23) Kim, H.; Boyle, L. N.; Goodchild, A. Delivery Process for an Office Building in the Seattle Central Business District. Transp. Res. Rec. 2018, 2672 (9), 173-183. 
https://doi.org/10.1177/0361198118798730.

(24) FedEx. 15.1.5 Inside Pickup and Delivery

https://www.fedex.com/us/developer/WebHelp/ws/2014/dvg/WS_DVG_WebHelp/15_1_ 5_Inside_Pickup_and_Delivery.htm (accessed Sep 13, 2020).

(25) University of Washington: Urban Freight Lab. The Final 50 Feet Urban Goods Delivery System Research Scan and Data Collection Project. 2018, 1-176.

(26) Ann Arbor, Michigan Population 2021 (Demographics, Maps, Graphs) https://worldpopulationreview.com/us-cities/ann-arbor-mi-population (accessed Mar 11, 2021).

(27) U.S. Census Bureau QuickFacts: Ann Arbor city, Michigan https://www.census.gov/quickfacts/annarborcitymichigan (accessed Mar 11, 2021).

(28) Stinson, M.; Pourabdollahi, Z.; Livshits, V.; Jeon, K.; Nippani, S.; Zhu, H. A Joint Model of Mode and Shipment Size Choice Using the First Generation of Commodity Flow Survey Public Use Microdata. Int. J. Transp. Sci. Technol. 2017, 6 (4), 330-343. https://doi.org/10.1016/j.ijtst.2017.08.002.

(29) Orozco, J. C. Analysis of Energy Efficiency in Truck-Drone "Last Mile" Delivery Systems, Master's Thesis, Purdue University Graduate School, 2019. https://doi.org/10.25394/PGS.8028974.V1.

(30) Department of Transportation, U.; Census Bureau, U. United States: 2012; 2012.

(31) Hurst, J. Jonathan W. Hurst: Building Robots to Work in Humans Spaces [ICRA 2020 WS - Legged Robots] - YouTube https://www.youtube.com/watch?v=BKjRVlzKEMI (accessed Sep 3, 2020).

(32) United States Environmental Protection Agency; (US-EPA). Vehicle Weight 
Classifications for the Emission Standards Reference Guide | Emission Standards

Reference Guide for On-road and Nonroad Vehicles and Engines | US EPA

https://www.epa.gov/emission-standards-reference-guide/vehicle-weight-classifications-

emission-standards-reference-guide (accessed Jul 20, 2020).

(33) Transportation Research and Analysis Computing Center; Argonne National Laboratory: Argonne, I. Argonne GREET Model https://greet.es.anl.gov/ (accessed Sep 13, 2020).

(34) IEEE Spectrum. Digit - ROBOTS: Your Guide to the World of Robotics https://robots.ieee.org/robots/digit/ (accessed Jun 30, 2020).

(35) Agility Robotics. Meet Digit - Agility Robotics https://www.agilityrobotics.com/meetdigit (accessed Aug 27, 2020).

(36) Occupational Safety and Health Administration (OSHA). Ergonomics eTool: Solutions for Electrical Contractors - Materials Handling: Heavy Lifting https://www.osha.gov/SLTC/etools/electricalcontractors/materials/heavy.html (accessed Sep 3, 2020).

(37) Emission Test Cycles: FTP-72 (UDDS) https://dieselnet.com/standards/cycles/ftp72.php (accessed Sep 10, 2020).

(38) Agility Robotics. Personal Communication. 2021.

(39) Kashiri, N.; Abate, A.; Abram, S. J.; Albu-Schaffer, A.; Clary, P. J.; Daley, M.; Faraji, S.; Furnemont, R.; Garabini, M.; Geyer, H.; Grabowski, A. M.; Hurst, J.; Malzahn, J.; Mathijssen, G.; Remy, D.; Roozing, W.; Shahbazi, M.; Simha, S. N.; Song, J. B.; SmitAnseeuw, N.; Stramigioli, S.; Vanderborght, B.; Yesilevskiy, Y.; Tsagarakis, N. An Overview on Principles for Energy Efficient Robot Locomotion. Front. Robot. AI 2018, 5 (DEC). https://doi.org/10.3389/frobt.2018.00129. 
(40) Agility Robotics - YouTube https://www.youtube.com/channel/UCN-StetwWuVYfMU2_NVj4A (accessed Sep 13, 2020).

(41) Argonne National Laboratory. Argonne GREET Model https://greet.es.anl.gov/ (accessed Jun 30, 2020).

(42) U.S. Department of Energy and U.S. Environmental Protection Agency. Fuel Economy of 2020 Vans

https://www.fueleconomy.gov/feg/PowerSearch.do?action=noform\&path=1\&year=2020\& mclass $=$ Vans\&srchtyp $=$ marClassMpg\&pageno $=1 \&$ rowLimit $=50($ accessed Nov 30, 2020).

(43) He, X.; Kim, H. C.; Ma, R.; Wallington, T. J.; Keoleian, G. A.; Kleine, R. De; Zhang, S.; Wu, Y. Energy Consumption Simulation for Connected and Automated Vehicles: EcoDriving Benefits Versus Automation Loads. SAE Int. J. Connect. Autom. Veh. [Manuscript Submitt. Publ.

(44) Jasiński, D.; Meredith, J.; Kirwan, K. A Comprehensive Framework for Automotive Sustainability Assessment. J. Clean. Prod. 2016, 135, 1034-1044. https://doi.org/10.1016/j.jclepro.2016.07.027.

(45) Cooney, G.; Hawkins, T. R.; Marriott, J. Life Cycle Assessment of Diesel and Electric Public Transportation Buses. J. Ind. Ecol. 2013, 17 (5), 689-699. https://doi.org/10.1111/jiec.12024.

(46) U.S. Department of Energy and U.S. Environmental Protection Agency. Fuel Economy https://www.fueleconomy.gov/ (accessed Nov 20, 2020).

(47) Barkenbus, J. N. Eco-Driving: An Overlooked Climate Change Initiative. Energy Policy 2010, 38 (2), 762-769. https://doi.org/10.1016/j.enpol.2009.10.021. 
(48) Lohn, A. What's the Buzz? The City-Scale Impacts of Drone Delivery; RAND Corporation, 2017. https://doi.org/10.7249/rr1718. 
APPENDIX - Supporting Information 


\title{
Supporting Information
}

\section{Life cycle greenhouse gas emissions for last-mile parcel delivery by automated vehicles and robots}

\author{
Luyao Li, Xiaoyi He, Gregory A. Keoleian, Hyung Chul Kim, Robert De Kleine, Timothy J. \\ Wallington, Nicholas, J, Kemp
}

Number of Pages: 18

Number of Tables: 3

Number of Figures: 11

The supporting information includes literature review data, spatial modeling, formulas, vehicle and robot operating steps, primary energy information and results, figures of automation impacts on GHG emissions and sensitivity analysis results. 
Table S1. Well-to-wheels delivery emissions per item or package from literature.

\begin{tabular}{|c|c|c|c|}
\hline Source & Delivery Type & $\begin{array}{c}\text { Emission } \\
\text { (g/item or } \\
\text { package) }\end{array}$ & Scope \\
\hline $\begin{array}{l}\text { Shahmoham } \\
\text { madi } 2020^{1}\end{array}$ & Tractor trailer, truck and car & 65 & Warehouse to store to customer \\
\hline \multirow{6}{*}{$\begin{array}{l}\text { Stolaroff et } \\
\text { al. } 2018^{2}\end{array}$} & $\begin{array}{c}\text { LDT ICEV van (150 packages per } 100 \\
\text { mile })\end{array}$ & 872 & \multirow{6}{*}{$\begin{array}{c}\text { Warehouse to customer } \\
\text { (including warehouse energy } \\
\text { usage) }\end{array}$} \\
\hline & $\begin{array}{l}\text { LDT BEV van (150 packages per100 } \\
\text { mile) }\end{array}$ & 772 & \\
\hline & $\begin{array}{l}\text { Class } 4 \text { diesel truck (151 packages per } \\
\qquad 100 \text { mile) }\end{array}$ & 1015 & \\
\hline & $\begin{array}{l}\text { Class } 4 \text { electric truck (151 packages } \\
\text { per100 mile) }\end{array}$ & 943 & \\
\hline & Small drone (1 package 2.2 mile) & 645 & \\
\hline & Large drone (1 package per 2.6 mile) & 1264 & \\
\hline \multirow{7}{*}{$\begin{array}{l}\text { P. Van Loon } \\
\text { et al. } 2015^{3}\end{array}$} & Pure player, Direct van delivery & 160 & \multirow{7}{*}{ Manufacturer to customer } \\
\hline & Pure player, parcel delivery network & 755 & \\
\hline & $\begin{array}{c}\text { Drop-shipping, parcel delivery } \\
\text { network }\end{array}$ & 690 & \\
\hline & Van delivery, local shop & 200 & \\
\hline & Click and collect & 230 & \\
\hline & Delivery van, warehouse to customer & 470 & \\
\hline & Conventional retail & 240 & \\
\hline \multirow{3}{*}{$\begin{array}{l}\text { Edwards et } \\
\text { al. } 2010^{4}\end{array}$} & $\begin{array}{l}\text { Standard delivery van }(<3.5 \mathrm{t}) 120 \\
\text { deliveries per } 50 \text { mile trip })\end{array}$ & 181 & Warehouse to customer \\
\hline & $\begin{array}{c}\text { Car (dedicated shopping trip of } 12.8 \\
\text { miles) }\end{array}$ & 4274 & \multirow{2}{*}{ Customer to store } \\
\hline & $\begin{array}{l}\text { Bus (dedicated shopping trip of } 8.8 \\
\text { miles, assuming average patronage) }\end{array}$ & 1265 & \\
\hline $\begin{array}{l}\text { Koiwanit } \\
2018^{5}\end{array}$ & Drone delivery system & $\begin{array}{l}79 \text { (per } \\
\text { package- } \\
\text { km) }\end{array}$ & $\begin{array}{c}\text { (Cradle to gate) } \\
\text { online shopping, business to } \\
\text { customer }\end{array}$ \\
\hline
\end{tabular}


Supporting Information

\begin{tabular}{|c|c|c|c|}
\hline \multirow{4}{*}{$\begin{array}{c}\text { Figliozzi } \\
2020^{6}\end{array}$} & $\begin{array}{c}\text { ICE van } \\
\text { Ridewalk Autonomous Delivery } \\
\text { Robots + mothership }\end{array}$ & \multirow{2}{*}{ N/A } & \multirow{2}{*}{ Grocery store to customer } \\
\cline { 2 - 3 } & Road Autonomous Delivery Robots & N/A & \\
\cline { 2 - 3 } & E-van & N/A & \\
\cline { 2 - 3 } & Drone & N/A & \multirow{2}{*}{ Depot to customer } \\
\hline $\begin{array}{c}\text { Orozco } \\
2019^{7}\end{array}$ & Drone-truck system & N/A & \\
\hline
\end{tabular}




\section{Formulas}

Production and EOL burden energy allocation (per package):

Primary energy per package $(M J / p k)=\frac{\text { Primary energy }(M J)}{\text { Packages delivered in lifetime }}$

For the vehicle and CAV subsystem

$$
=\text { primary energy }(M J) \times \frac{1}{\text { lifetime distance }(\text { miles })} \times \frac{\text { miles }}{\text { stop }} \times \frac{\text { stops }}{\text { package }}
$$

$\underline{\text { For the robot }}$

$$
=\text { primary energy }(M J) \times \frac{1}{\text { lifetime steps }} \times \frac{\text { steps }}{\text { package }}
$$

\section{Use phase burden energy (per package):}

For the vehicle

$$
\begin{aligned}
& \text { primary energy per package }(M J / p k) \\
& =\frac{\text { primary energy }(M J)}{\text { gallon }} \times \frac{\text { gallons }}{\text { mile }} \\
& \times \frac{(8+\text { dist. } b / w \text { stops } \times \text { packages })(\text { miles })}{\text { packages }}
\end{aligned}
$$

For the CAV subsystem and robot

$$
\begin{aligned}
& \text { primary energy per package }\left(\frac{M J}{p k}\right) \\
& =\frac{\text { operating energy }(W h)+\text { standby energy }(W h)}{\text { package }} \\
& \quad \times \frac{\text { primary energy }(M J)}{\text { delivered energy }(W h)}
\end{aligned}
$$

Where

Operating Energy $(W h)=$ Operating Power $(W) \times$ Operating Time $(h)$

Standby Energy $(W h)=$ Standby Power $(W) \times$ Standby time $(h)$ 


\section{Formulas (cont.)}

\section{Production and EOL burden GHG emissions allocation (per package):}

$G H G$ emssions per package $(g \mathrm{CO} 2 e / p k)=\frac{\text { Total GHG emssions }(g \mathrm{CO} 2 e)}{\text { Packages delivered in lifetime }}$

$\underline{\text { For the vehicle and CAV subsystem }}$

$$
=\text { Total GHG emssions }(g \text { CO2e }) \times \frac{1}{\text { lifetime distance }(\text { miles })} \times \frac{\text { miles }}{\text { stop }} \times \frac{\text { stops }}{\text { package }}
$$

For the robot

$$
=\text { Total GHG emssions }(g \mathrm{CO} 2 e) \times \frac{1}{\text { lifetime steps }} \times \frac{\text { steps }}{\text { package }}
$$

\section{Use phase burden GHG emissions (per package):}

For the vehicle

$$
\begin{aligned}
\text { GHG emssions per package }(\mathrm{g} C \mathrm{CO} e / \mathrm{pk}) & \\
& =\frac{\text { GHG emssions }(\mathrm{gCO} 2 \mathrm{C})}{\text { gallon }} \times \frac{\text { gallons }}{\text { mile }} \\
& \times \frac{(8+\text { dist. } \mathrm{b} / \mathrm{w} \text { stops } \times \text { packages })(\text { miles })}{\text { packages }}
\end{aligned}
$$

For the CAV subsystem and robot

$$
\begin{aligned}
\text { GHG emssions per package }\left(\frac{g C O 2 e}{p k}\right) \\
=\frac{\text { operating energy }(W h)+\text { standby energy }(W h)}{\text { package }} \\
\times \frac{\text { GHG emssions }(g C O 2 e)}{\text { delivered energy }(W h)}
\end{aligned}
$$

Where

Operating Energy $(W h)=$ Operating Power $(W) \times$ Operating Time $(h)$

Standby Energy $(W h)=$ Standby Power $(W) \times$ Standby time $(h)$ 


\section{Spatial modeling details}

Spatial modeling was conducted for the $125 \mathrm{ft}^{3}$ cargo (V125 van) and $350 \mathrm{ft}^{3}$ cargo (V350 van) with a 20-inch-wide aisle and mixed-size packages packed on both sides of the cargo (shown in Figure S1). This spatial model results in an estimated effective load volume of $40 \%$ for the V125 van and 35\% for the V350 van. The 20-inch aisle takes up 40\% and 35\% of the cargo space and the additional void space takes up $20 \%$ and $30 \%$ of the cargo space for the V125 and V350 vans, respectively. A 40\% effective load for the V125 van carries a maximum of 80 mixed-size packages and a 35\% effective load for V350 van carries up to 180 mixed-size packages.

Our base case assumed 80 packages for the V125 and 180 packages for the V350 based on spatial modeling. We detail the effective load percentages we used to arrive at load sizes of 80 and 180 packages (see Figure S1 b \& c).

Our spatial modeling of a typical loading scenario is based on inputs from a local delivery company and various package sizes. We consider a load of varied package sizes and void space that includes the aisle space and additional void space that are above and between the packages. We modeled a 20 -inch wide aisle in the cargo space for humans or robots to move through.

The aisle occupies $40 \%$ of the V125 cargo volume, leaving $60 \%$ for packages and associated additional void space. The V125 holds (15) $0.17 \mathrm{cu}-\mathrm{ft}$ boxes, (8) $0.38 \mathrm{cu}-\mathrm{ft}$ boxes, (11) $0.96 \mathrm{cu}-\mathrm{ft}$ boxes, (3) $1.17 \mathrm{cu}-\mathrm{ft}$ boxes, and (3) $1.89 \mathrm{cu}-\mathrm{ft}$ boxes on either side of the aisle for a total of $40 \times 2=\mathbf{8 0}$ packages. These 80 packages with their associated volume results in a $\mathbf{4 0 \%}$ effective load for the V125 van (leaving $20 \%$ additional void space).

The aisle occupies $35 \%$ of the V350 cargo volume, leaving $65 \%$ for packages and associated additional void space. The V350 holds (21) $0.17 \mathrm{cu}-\mathrm{ft}$ boxes, (26) $0.38 \mathrm{cu}-\mathrm{ft}$ boxes, (31) $0.96 \mathrm{cu}-\mathrm{ft}$ boxes, (7) $1.17 \mathrm{cu}-\mathrm{ft}$ boxes, and (5) $1.89 \mathrm{cu}-\mathrm{ft}$ boxes on either side of the aisle for a total of $90 \times 2=\mathbf{1 8 0}$ packages. This results in a 35\% effective load for the V350 van (leaving $30 \%$ additional void space).

As shown in Figure S1(a), the V125 can hold 26-294 packages depending on package sizes when considering a 20 -inch aisle space ( $40 \%$ of V125 cargo) and additional $20 \%$ void space (the space that are above the packages or between the packages). We calculated that the V350 can hold 66 - 741 packages depending on package sizes when considering a 20-inch aisle (35\% of V350 cargo) and additional $30 \%$ void space. 


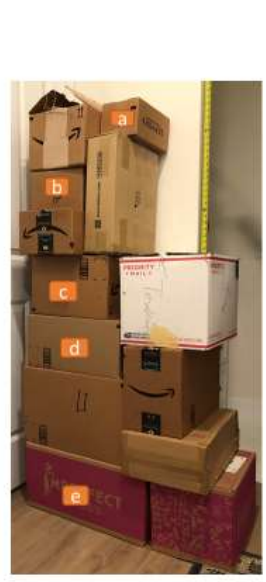

\begin{tabular}{|c|c|c|c|c|c|c|c|}
\hline & & & & & & $\begin{array}{c}\text { V125 } \\
\text { (left } 19.6 \text { in } \\
\text { width aisle and } \\
20 \% \text { additional } \\
\text { void space - } \\
50 \text { cu-ft) }\end{array}$ & $\begin{array}{c}\text { V350 } \\
\text { (left } 19.6 \text { in } \\
\text { width aisle and } \\
30 \% \text { additional } \\
\text { void space - } \\
126 \text { cu-ft) }\end{array}$ \\
\hline Box & $\stackrel{\mathrm{L}}{\text { (in) }}$ & $\begin{array}{l}\text { W } \\
\text { (in) }\end{array}$ & $\begin{array}{l}\mathrm{H} \\
\text { (in) }\end{array}$ & $\begin{array}{l}\text { Volume } \\
\text { (cu-ft) }\end{array}$ & $\begin{array}{c}\text { Package } \\
\text { Weight } \\
\text { (lbs.) }\end{array}$ & \# boxes & \# boxes \\
\hline a & 10 & 6.25 & 4.75 & 0.17 & 0.44 & 294 & 741 \\
\hline$b$ & 12 & 9 & 6 & 0.38 & 4.84 & 131 & 331 \\
\hline c & 14 & 12.5 & 9.5 & 0.96 & 10.34 & 52 & 131 \\
\hline d & 17.25 & 14.25 & 8.25 & 1.17 & 15.4 & 42 & 107 \\
\hline e & 21.5 & 14.5 & 10.5 & 1.89 & 26.4 & 26 & 66 \\
\hline
\end{tabular}

(a).

*Note that the package capacity is constrained by volume, not on package weight.

(b).

Transit Connect Cargo, ( $w 48.7$ between wheelhouse - aisle $19.6=29.1$ ) $/ 2=\min 14.55$ inch width at each side

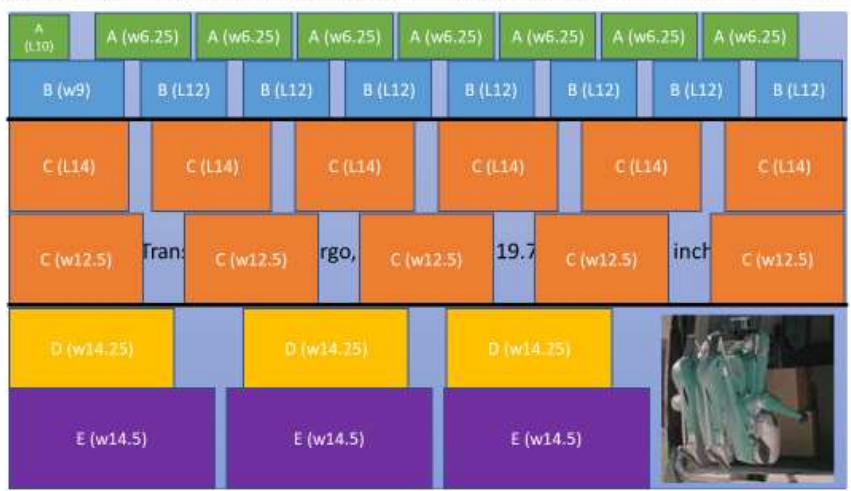

Transit Connect L $87.6 \times \mathrm{H} 49.8$

A $\times 15(8+7)$

$\mathrm{B} \times 8$

C $\times 11$

D $\times 3$

Ex 3

One side

Total 40

packages $* 2$

$=80$

packages

total

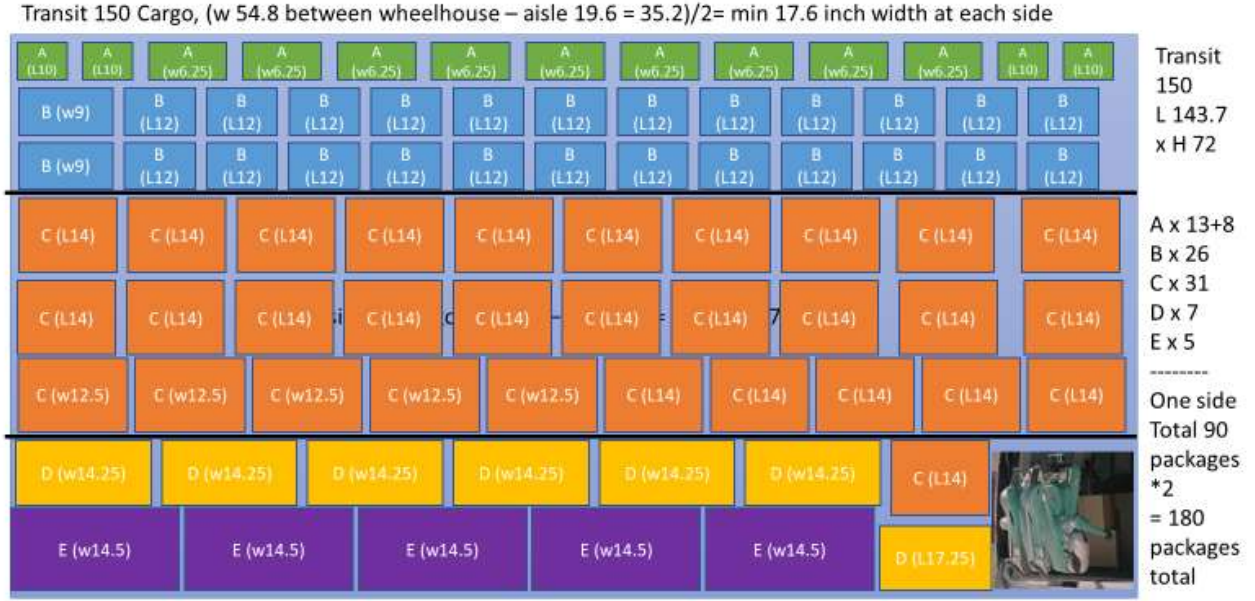

(c).

Figure S1. Mixed sized package modeling with a 20-inch wide isle in the cargo. (a) Personally received packages in five different sizes, (b) Spatial modeling for Transit connect (V125), which has a 40\% effective load volume result with 80 packages (c) Spatial modeling for Transit 150 (V350), which has a 35\% effective load volume result with 180 packages. 


\section{Final-50-feet delivery robot}

Digit (See Figure S2) is a bipedal robot that's developed by Agility Robotics. ${ }^{8}$ The V1 weighs $42.2 \mathrm{~kg}$ and stands $155 \mathrm{~cm}$ tall. ${ }^{9}$ The V3 weighs $44.6 \mathrm{~kg} .{ }^{10}$ It has legged mobility with perception and arms. It can get up off the ground, lift boxes, go outdoors and in human environments; it can map environments ${ }^{9}$.
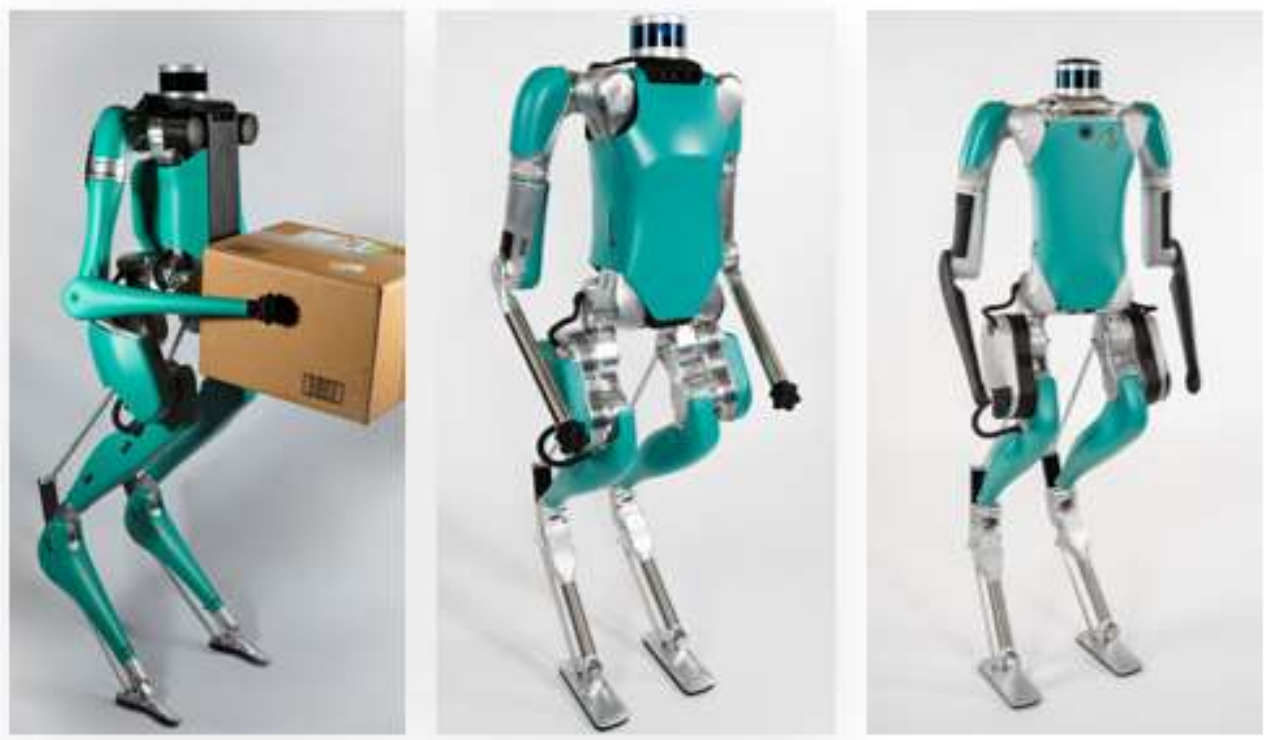

Figure S2. Agility Robotics Digit models, v1 (left), v2 (center), v3 (right). [Reproduced with permission from Agility Robotics] 
Supporting Information

Table S2. Vehicle and Robot operating steps

\begin{tabular}{|c|c|c|c|c|}
\hline \# step & Robot Action & Time, s & $\begin{array}{l}\text { Robot Power } \\
\text { Usage, } W\end{array}$ & Vehicle Action \\
\hline $\mathbf{0}$ & $\begin{array}{l}\text { Sitting in a vehicle } \\
\text { at the hub }\end{array}$ & - & 0 (Not in use) & Not in operation \\
\hline 1 & Sitting in vehicle & 720 (one time) & $150(\text { standby })^{11}$ & $\begin{array}{l}\text { In operation, } 4 \text { miles } @ 20 \\
\text { miles/hour from hub to the } \\
\text { delivery zone. } \sim 12 \text { mins }\end{array}$ \\
\hline 2 & $\begin{array}{l}\text { Sitting in a vehicle } \\
\text { between stops }\end{array}$ & 90 & $150(\text { standby })^{11}$ & 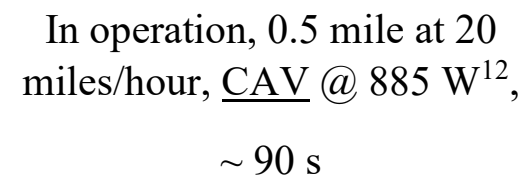 \\
\hline 3 & $\begin{array}{l}\text { Unload/unfold itself } \\
\text { from the vehicle }\end{array}$ & 10 & \multirow{7}{*}{$\begin{array}{l}4600^{10} \text { (in } \\
\text { operation) }\end{array}$} & \\
\hline 4 & $\begin{array}{l}\text { Unload package } \\
\text { from the vehicle }\end{array}$ & 6 & & \\
\hline 5 & $\begin{array}{l}\text { Transport package } \\
\text { to the doorway }\end{array}$ & 30 & & 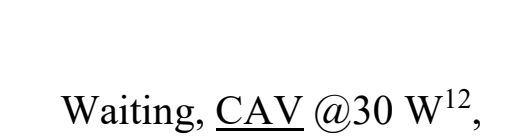 \\
\hline 6 & $\begin{array}{l}\text { Put down the } \\
\text { package }\end{array}$ & 8 & & $\begin{array}{c}\text { total } 100 \mathrm{~s} \\
{[\text { Human may use less than } 60 \mathrm{~s}]}\end{array}$ \\
\hline 7 & Stand up by itself & 6 & & \\
\hline 8 & $\begin{array}{c}\text { Walking back to the } \\
\text { vehicle }\end{array}$ & 30 & & \\
\hline 9 & $\begin{array}{l}\text { Load/fold itself into } \\
\text { the vehicle }\end{array}$ & 10 & & \\
\hline 10 & $\begin{array}{c}\text { Sitting in the } \\
\text { vehicle after } \\
\text { delivered all parcels }\end{array}$ & 720 (one time) & $150\left(\right.$ standby) ${ }^{11}$ & $\begin{array}{l}\text { In operation, } 4 \text { miles } @ 20 \\
\text { miles/hour back to the hub. } \\
\sim 12 \text { mins }\end{array}$ \\
\hline
\end{tabular}

*Note: Repeat step 2-9 for each stop per route. Repeat $4-8$ if there are multiple packages at one stop. 
Table S3. Vehicle, robot, and CAV subsystem weight, primary energy use and GHG emissions in production and EOL burden values

\begin{tabular}{|c|c|c|c|}
\hline & $\begin{array}{c}\text { Weight } \\
\text { (kg) }\end{array}$ & $\begin{array}{l}\text { Primary energy use in } \\
\text { production and EOL } \\
\text { (GJ) }\end{array}$ & $\begin{array}{l}\text { GHG emissions in } \\
\text { production and EOL } \\
\text { (metric tons CO2eq.) }\end{array}$ \\
\hline V125-ICEV & 2,040 & 118 & 7.97 \\
\hline V125-BEV & 2,568 & 197 & 13.1 \\
\hline V350-ICEV & 2,370 & 135 & 9.20 \\
\hline V350-BEV & 3,380 & 289 & 19.1 \\
\hline Robot & 44.6 & 5.2 & 0.327 (exclude EOL) \\
\hline CAV subsystem & 67.1 & 19.8 & 1.20 \\
\hline
\end{tabular}

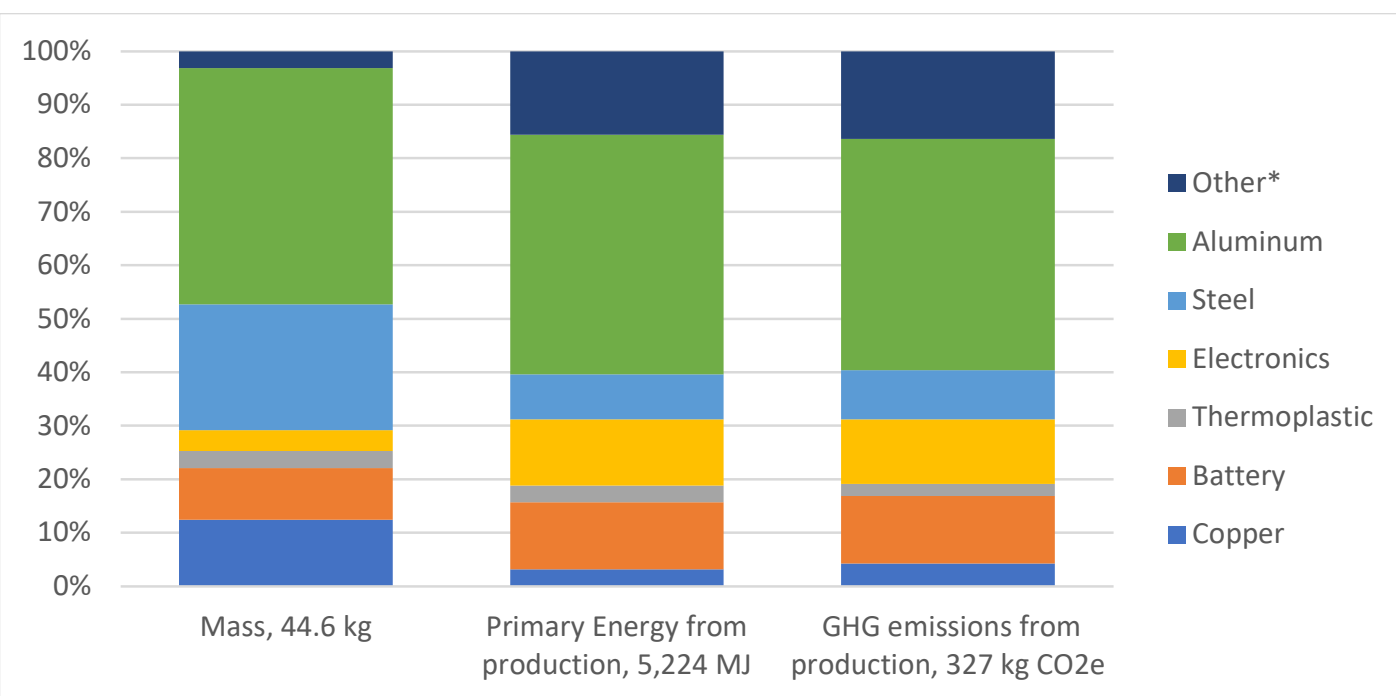

Figure S3. Robot weight, production burden energy, and production burden GHGs (44.6 kg, $5,224 \mathrm{MJ}$ and $327 \mathrm{~kg}$ CO2e, respectively) breakdown by components/materials. 


\section{Vehicle Life Cycle Energy Use}

The $24 \mathrm{mpg}$, 85mpgge, $14 \mathrm{mpg}$, 47mpgge fuel efficiency result in the well-to-wheels total primary energy use of $6.21,3.11,10.64$, and $5.64 \mathrm{MJ} / \mathrm{mile}$ for V125-ICEV, V125-BEV, V350ICEV, and V350-BEV, respectively ${ }^{13,14}$. To allocate energy use and GHG emissions from per mile to per package, the delivery densities of 1.67 ( $=80$ packages / 48 miles for V125) and 1.84 (=180/98 for V350) packages per mile are considered.

The CAV subsystem has a total weight of $67.1 \mathrm{~kg}$, total primary energy of $19,700 \mathrm{MJ}$ for production and $100 \mathrm{MJ}$ for end of life (EOL).

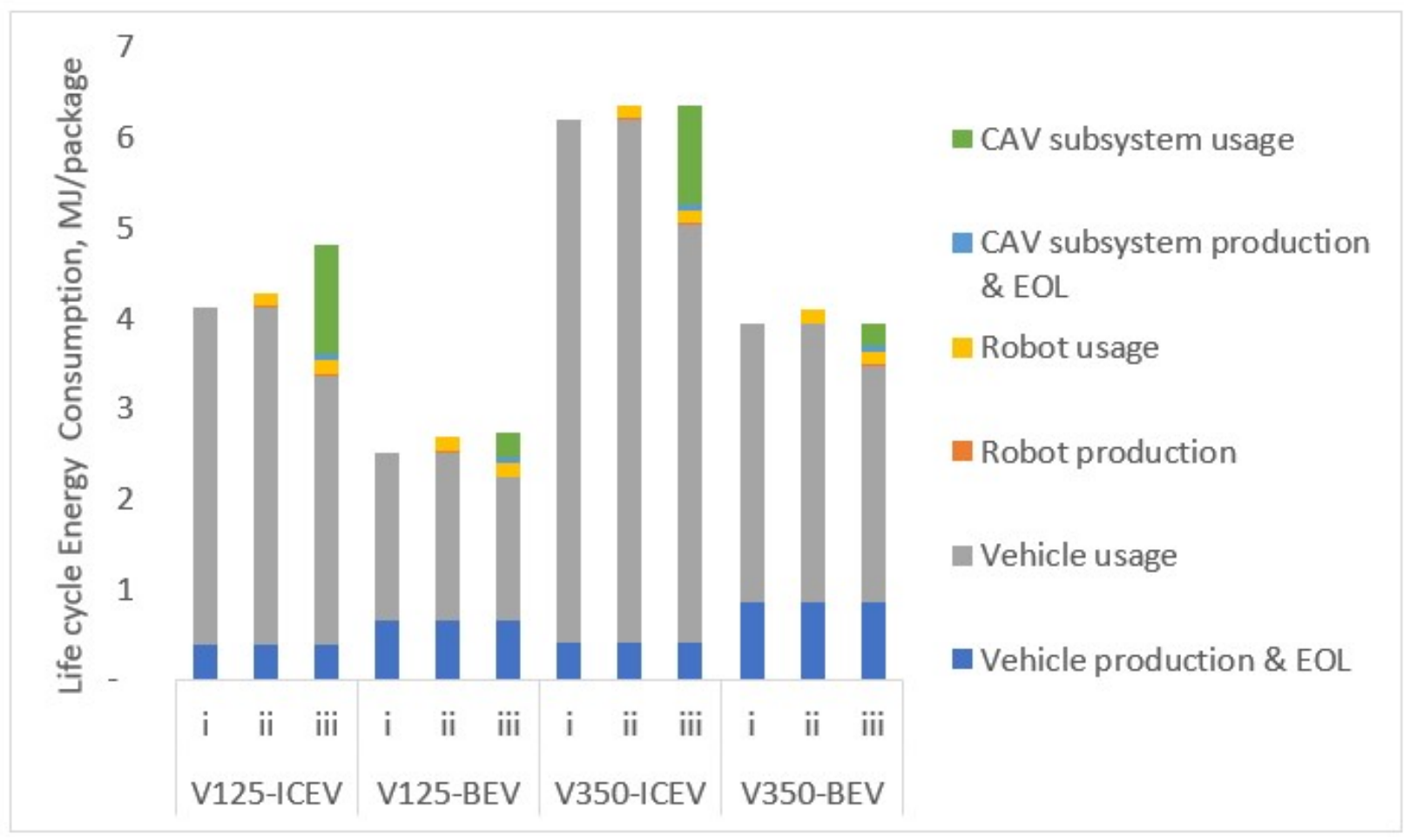

Figure S4. Base case life cycle energy per package for (i) conventional, (ii) partially automated, and (iii) fully automated delivery scenarios. 


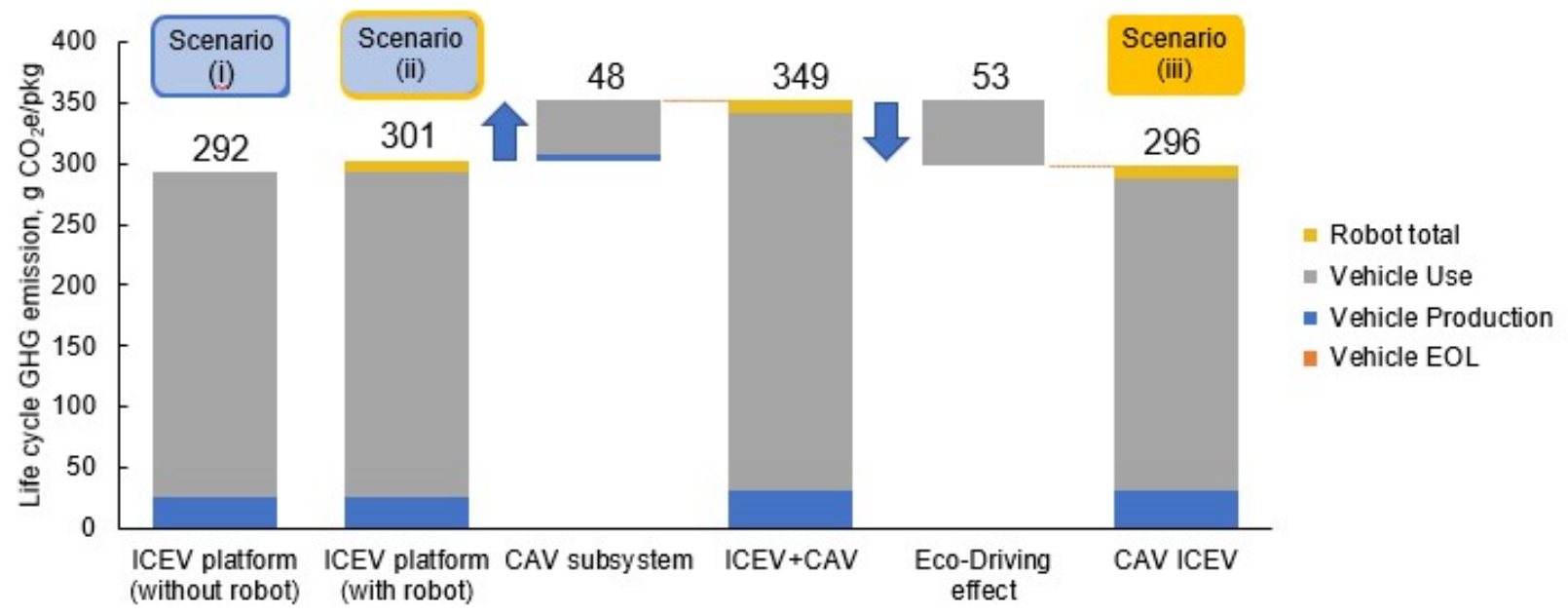

Figure S5. Automation impacts on GHG emissions for the V125-ICEV platform, including increased emissions from the robot (production and use) and CAV subsystem and decreased emissions due to eco-driving.

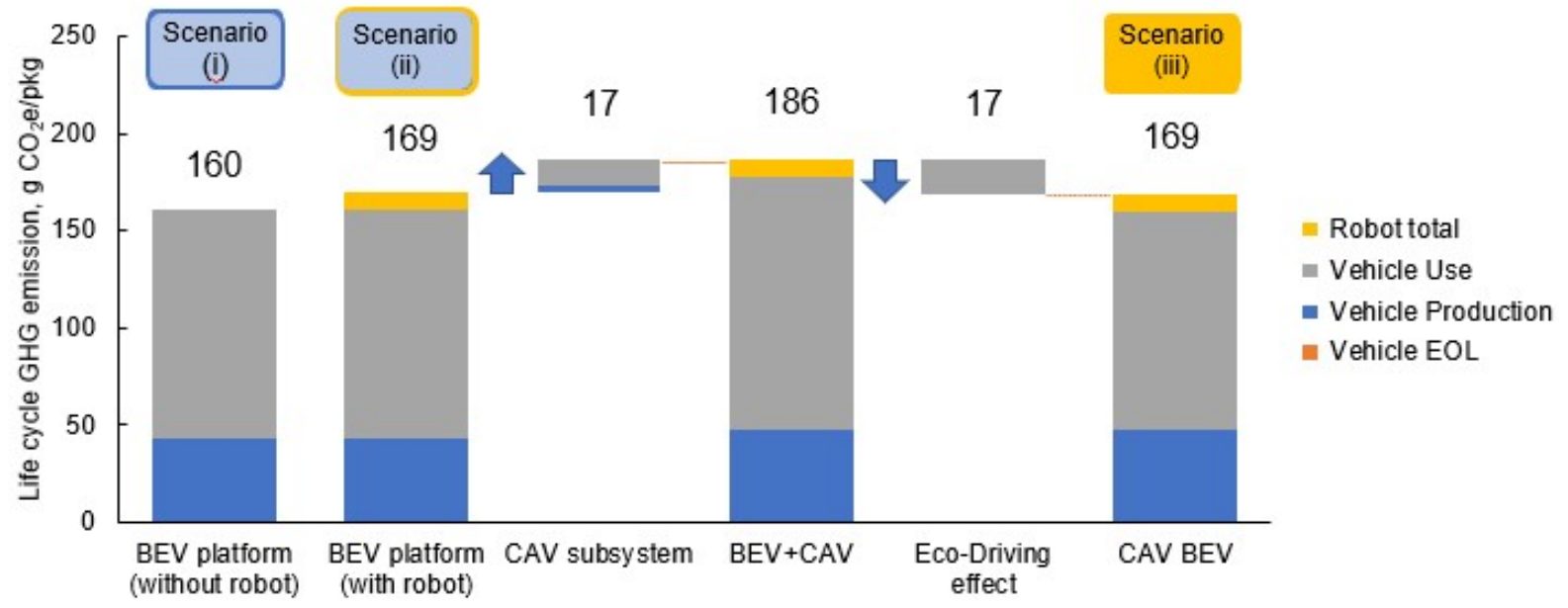

Figure S6. Automation impacts on GHG emissions for the V125-BEV platform, including increased emissions from the robot (production and use) and CAV subsystem and decreased emissions due to eco-driving. 
Supporting Information

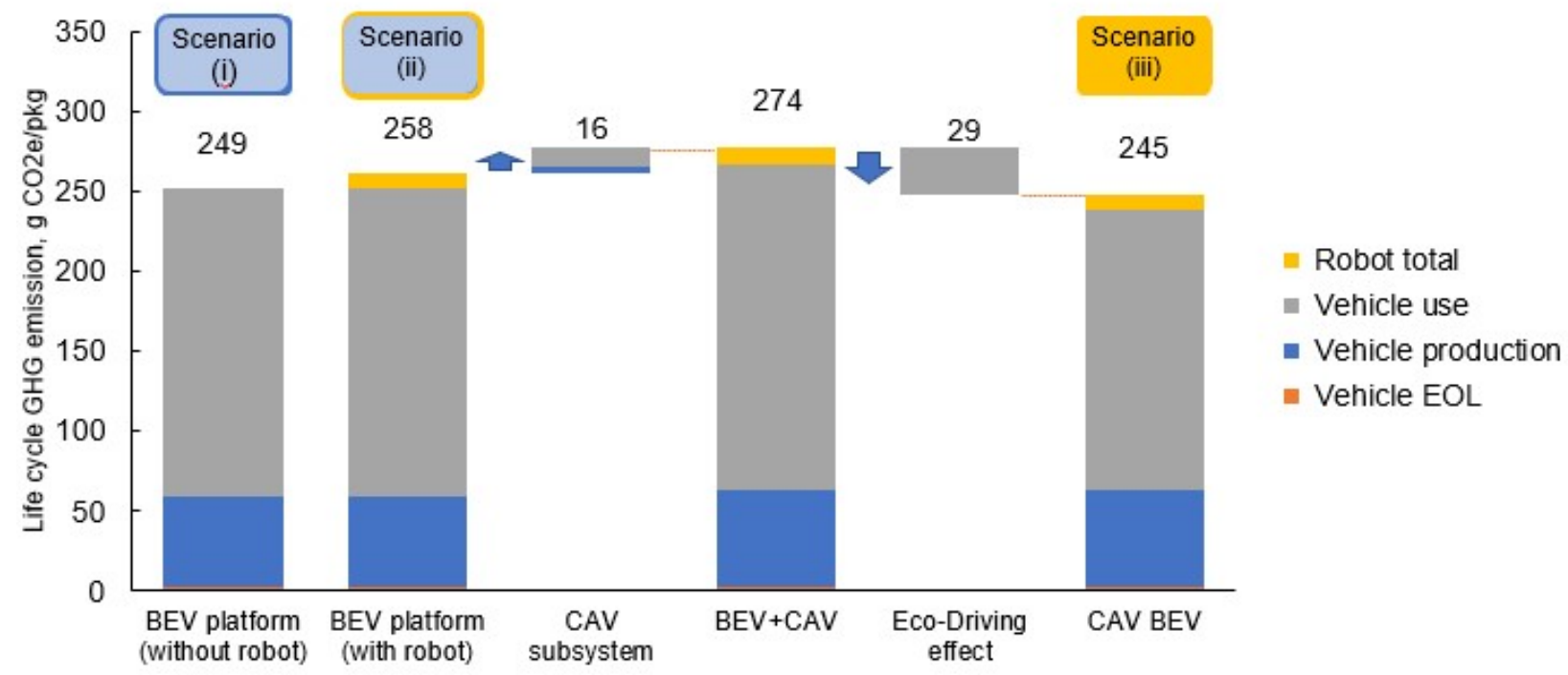

Figure S7. Automation impacts on GHG emissions for the V350-BEV platform, including increased emissions from the robot total (production and use) and CAV subsystem and decreased emissions due to eco-driving. 
Supporting Information

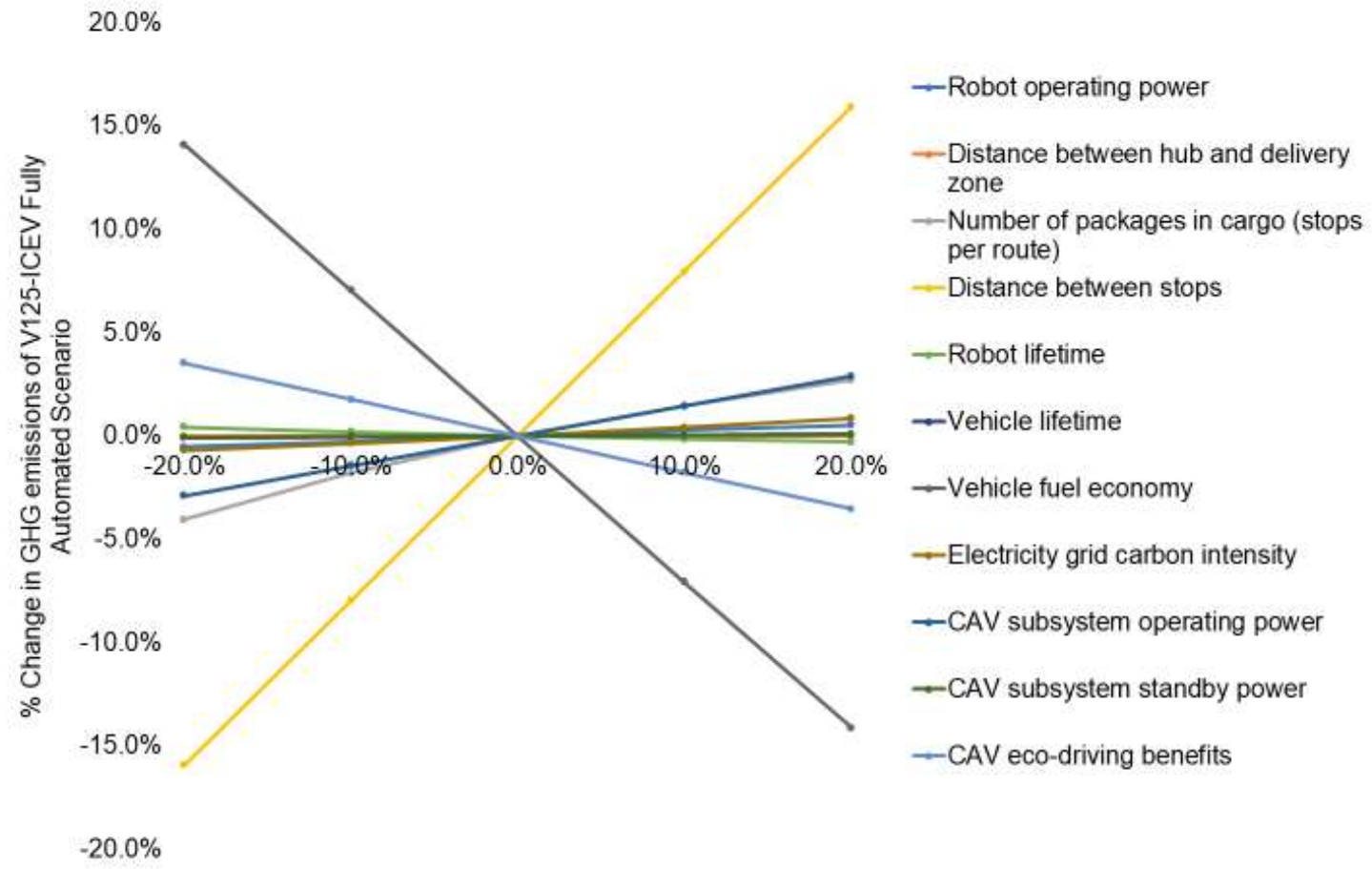

Figure S8. Sensitivity analysis on parameters with uncertainty (conducted with automated V125ICEV GHG emissions) 
Supporting Information

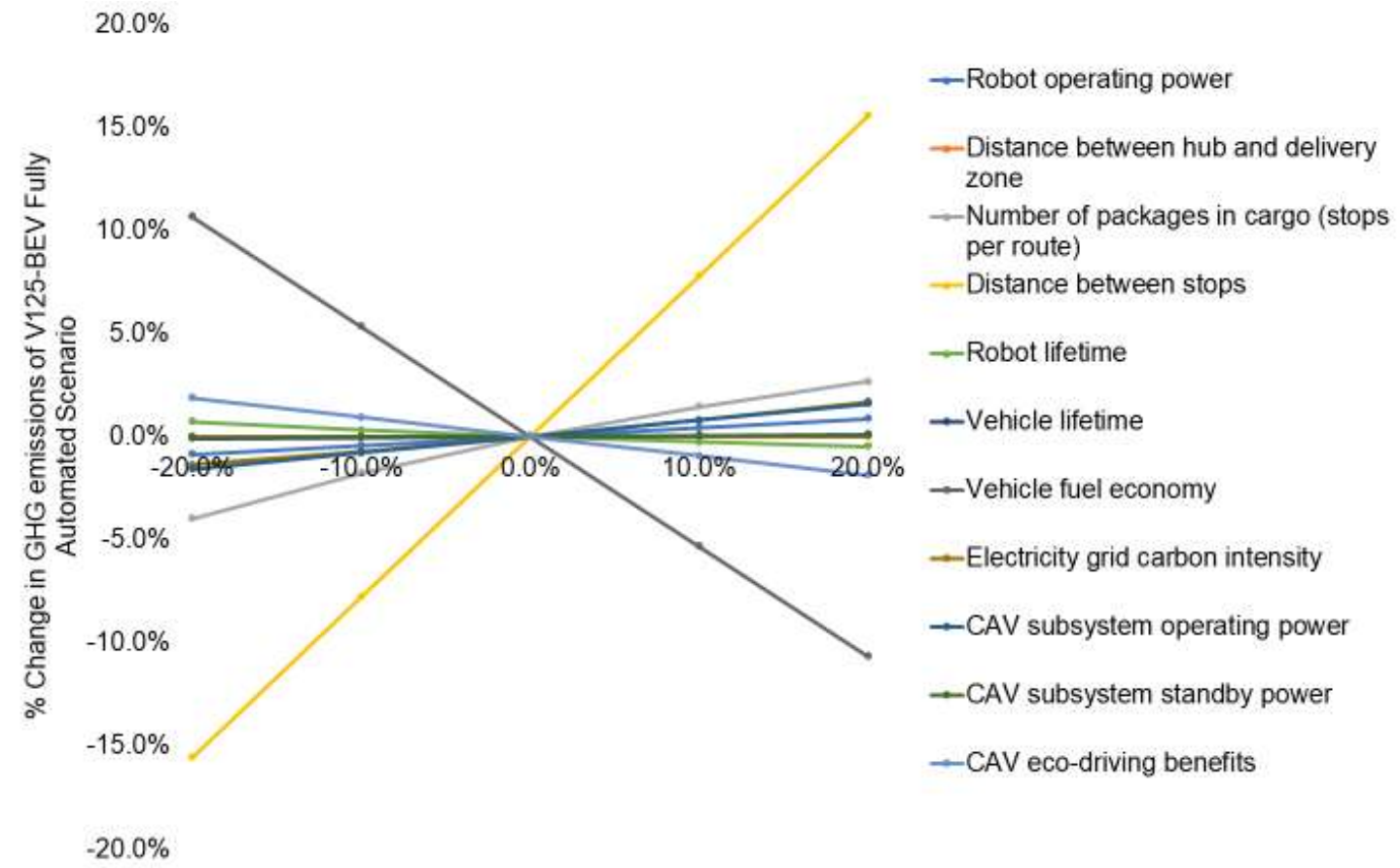

Figure S9. Sensitivity analysis on parameters with uncertainty (conducted with automated V125BEV GHG emissions)

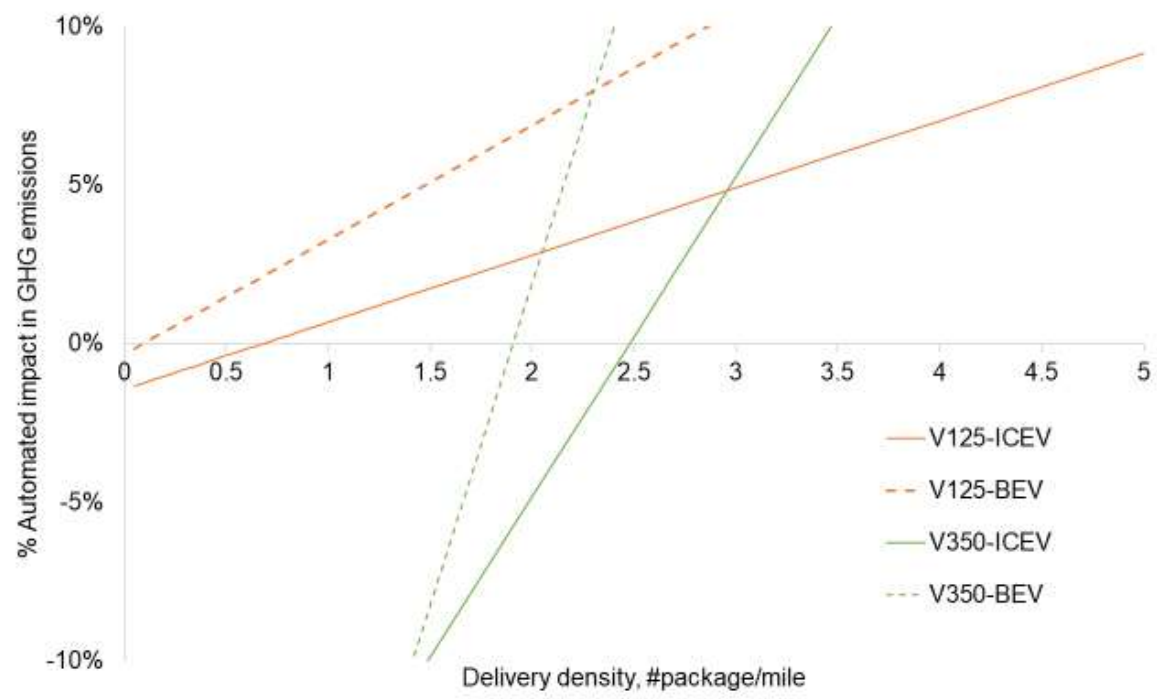

Figure S10. Automation impact (compared to conventional) on GHG emissions with delivery density in \#package/mile 
Supporting Information

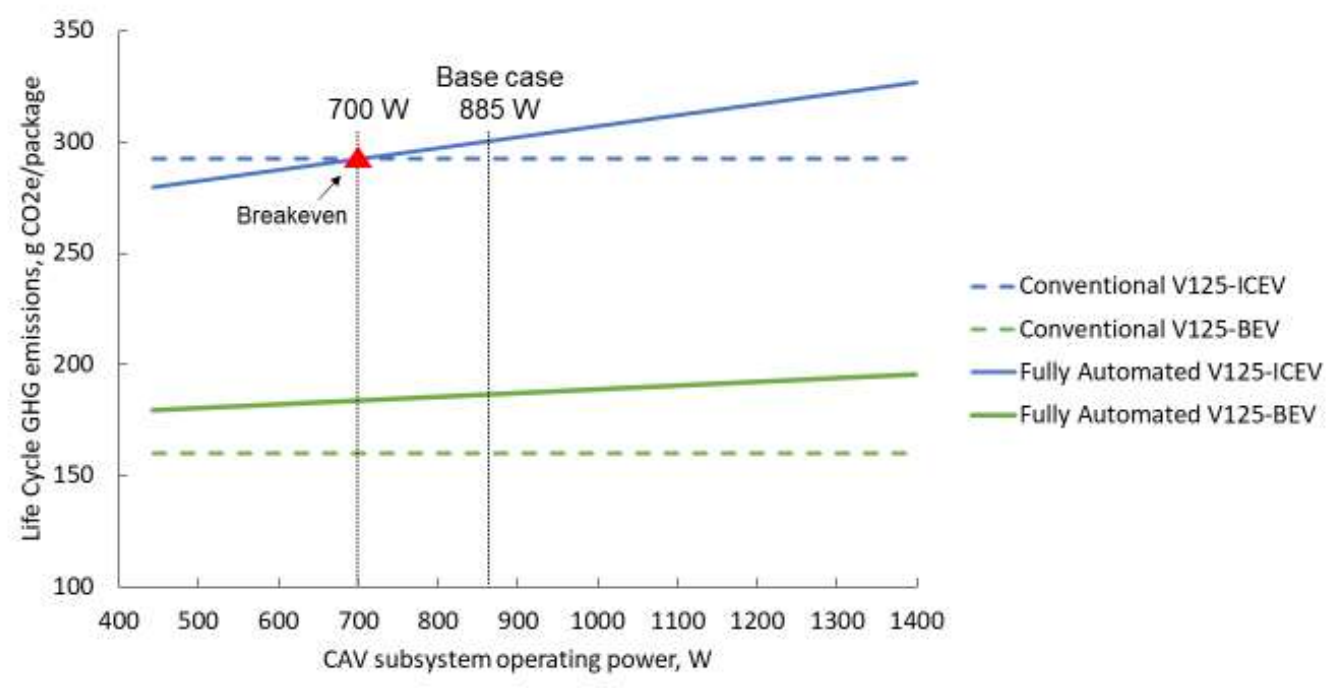

Figure S11. Life cycle GHGs result with various CAV subsystem operating power requirements for the V125. The breakeven point is a $700 \mathrm{~W} C A V$ subsystem operating power for fully automated V125-ICEV to have the same GHGs per package as its conventional scenario without changing other parameters. 


\section{References}

(1) Shahmohammadi, S.; Steinmann, Z. J. N.; Tambjerg, L.; Van Loon, P.; King, J. M. H.; Huijbregts, M. A. J. Comparative Greenhouse Gas Footprinting of Online versus Traditional Shopping for Fast-Moving Consumer Goods: A Stochastic Approach. Environ. Sci. Technol. 2020, 54 (6), 3499-3509. https://doi.org/10.1021/acs.est.9b06252.

(2) Stolaroff, J. K.; Samaras, C.; O’Neill, E. R.; Lubers, A.; Mitchell, A. S.; Ceperley, D. Energy Use and Life Cycle Greenhouse Gas Emissions of Drones for Commercial Package Delivery. Nat. Commun. 2018, 9 (1), 1-13. https://doi.org/10.1038/s41467-01702411-5.

(3) Van Loon, P.; Deketele, L.; Dewaele, J.; McKinnon, A.; Rutherford, C. A Comparative Analysis of Carbon Emissions from Online Retailing of Fast Moving Consumer Goods. $J$. Clean. Prod. 2015, 106 (2015), 478-486. https://doi.org/10.1016/j.jclepro.2014.06.060.

(4) Edwards, J. B.; McKinnon, A. C.; Cullinane, S. L. Comparative Analysis of the Carbon Footprints of Conventional and Online Retailing: A "Last Mile" Perspective. Int. J. Phys. Distrib. Logist. Manag. 2010, 40 (1-2), 103-123. https://doi.org/10.1108/09600031011018055.

(5) Koiwanit, J. Analysis of Environmental Impacts of Drone Delivery on an Online Shopping System. Adv. Clim. Chang. Res. 2018, 9 (3), 201-207. https://doi.org/10.1016/j.accre.2018.09.001.

(6) Figliozzi, M. A. Carbon Emissions Reductions in Last Mile and Grocery Deliveries Utilizing Air and Ground Autonomous Vehicles. Transp. Res. Part D Transp. Environ. 2020, 85. https://doi.org/10.1016/j.trd.2020.102443.

(7) Orozco, J. C. Analysis of Energy Efficiency in Truck-Drone "Last Mile” Delivery Systems, Master's Thesis, Purdue University Graduate School, 2019. https://doi.org/10.25394/PGS.8028974.V1.

(8) Agility Robotics. Meet Digit - Agility Robotics https://www.agilityrobotics.com/meetdigit (accessed Aug 27, 2020).

(9) IEEE Spectrum. Digit - ROBOTS: Your Guide to the World of Robotics https://robots.ieee.org/robots/digit/ (accessed Jun 30, 2020).

(10) Agility Robotics. Personal Communication. 2021.

(11) Kashiri, N.; Abate, A.; Abram, S. J.; Albu-Schaffer, A.; Clary, P. J.; Daley, M.; Faraji, S.; Furnemont, R.; Garabini, M.; Geyer, H.; Grabowski, A. M.; Hurst, J.; Malzahn, J.; Mathijssen, G.; Remy, D.; Roozing, W.; Shahbazi, M.; Simha, S. N.; Song, J. B.; SmitAnseeuw, N.; Stramigioli, S.; Vanderborght, B.; Yesilevskiy, Y.; Tsagarakis, N. An Overview on Principles for Energy Efficient Robot Locomotion. Front. Robot. AI 2018, 5 (DEC). https://doi.org/10.3389/frobt.2018.00129.

(12) Kemp, N. J.; Keoleian, G. A.; He, X.; Kasliwal, A. Life Cycle Greenhouse Gas Impacts of a Connected and Automated SUV and Van. Transp. Res. Part D Transp. Environ. 2020, 83. https://doi.org/10.1016/j.trd.2020.102375. 
Supporting Information

(13) U.S. Department of Energy and U.S. Environmental Protection Agency. Fuel Economy https://www.fueleconomy.gov/ (accessed Nov 20, 2020).

(14) Argonne National Laboratory. Argonne GREET Model https://greet.es.anl.gov/ (accessed Jun 30, 2020). 